\title{
The Expression of Interleukin-1 $\beta$ Is Regulated by DNA Methylation in Microglia of Hippocampus to Participate Postoperative Cognitive Dysfunction in Aged Mice
}

\section{Yin Gao}

Xuzhou Medical University https://orcid.org/0000-0002-1832-296X

Li Yang

Xuzhou Medical University

Xiu Yang

Xuzhou Medical University

Jing-Ru Hao

Xuzhou Medical University

Xiao-Ran Shen

Xuzhou Medical University

Xu Li

Xuzhou Medical University

Yue-Ying Liu

Xuzhou Medical University

Le Liu

Xuzhou Medical University

Kun Tong

Xuzhou Medical University

Yue You

Xuzhou Medical University

Di-Shi Chen

Xuzhou Medical University

Nan Sun

Xuzhou Medical University

Can Gao ( $\sim$ gaocan@xzhmu.edu.cn )

Xuzhou Medical University https://orcid.org/0000-0001-5552-9639

Research 
Keywords: DNA methylation, IL-1ß, microglia, POCD, Synaptic plasticity

Posted Date: July 13th, 2021

DOI: https://doi.org/10.21203/rs.3.rs-670804/v1

License: (c) (1) This work is licensed under a Creative Commons Attribution 4.0 International License. Read Full License 


\section{Abstract}

\section{Background}

Postoperative cognitive dysfunction (POCD) is one of the common postoperative complications in the elderly. The main clinical manifestation is memory impairment, which can cause permanent damage and even dementia in severe cases. However, the pathogenesis of POCD is still unknown. Age and neuroinflammation are known to be closely related to its occurrence, while DNA methylation is very important for transcriptional silencing and neuroinflammation. Consequently, this study intended to establish a mouse model of POCD to explore the role of DNA methylation in regulating the expression of interleukin-1 $\beta$ which participated POCD in aged mice.

Methods

POCD model was established by exploratory laparotomy and evaluated by new object experiment and $Y$ maze test. In addition, ELISA, RT-PCR, Western blotting, immunofluorescence, microglia isolation and flow cytometry methods were used to detect the inflammatory state of dorsal hippocampal after surgery. Moreover, MSP, MeDIP and IL-1 $\beta$ promoter DNA methylation sequencing were used to explore the regulation of DNA methylation on IL-1 $\beta$ in this model. Finally, Golgi staining and Western blotting were used to further explore the role of IL-1 $\beta$ in POCD and its possible mechanisms.

Results

Cognitive impairment was observed in aged but not adult mice at 1 day after surgery. There was a significant correlation between the level of IL-1 $\beta$ in dorsal hippocampus and the performance of cognitive function. The microglia in the dorsal hippocampus was activated and the IL-1 $\beta$ promoter DNA methylation was decreased in the aged mice. The increased expression of IL-1 $\beta$ impaired synaptic plasticity and hippocampus-dependent memory formation. Intracerebroventricular administration of IL-1 $\beta$ receptor antagonist could prevent the cognitive impairment of aged mice after surgery, reverse the decrease of dendritic spine density and synapse-associated protein expression induced by surgery.

Conclusion

DNA methylation regulation may be an important mechanism for greater susceptibility to POCD in aged mice by regulating the expression of IL-1 $\beta$. IL-1 $\beta$ inhibiting prevented surgery-induced cognitive decline and synaptic plasticity dysfunction. The research also provided a new target for the clinical prevention of the occurrence of POCD in the elderly.

\section{Introduction}

Postoperative cognitive dysfunction (POCD) is a recognized clinical phenomenon, which is characterized by a disturbance in memory, intellectual ability, and executive function, adversely affecting quality of life, social dependence and mortality [1]. The incidence of POCD in middle-aged patients is $19.2 \%$ [2], and up 
to $52 \%$ in aged patients [3, 4]. Increased susceptibility to POCD was also found in aged animals [5-8]. However, it remains debatable why this complication occurs highly in the aged individuals.

In the aging process, excessive release of IL-1 $\beta$ and microglia priming are usually considered as the main culprit of POCD as IL-1 $\beta$ and microglia are at the nexus of crosstalk between neuroinflammation and abnormal neuronal functioning and synaptic injury $[9,10]$. IL-1 $\beta$, IL-1 $\beta$ receptor and the naturally occurring interleukin-1 receptor antagonist (IL-1 ra) are all found at comparatively high levels in the hippocampus, a brain structure known to be critical for spatial and contextual memory $[11,12]$. However, It is not clear how anesthesia and surgery affect the excessive release of IL-1 $\beta$ in the aged individuals and how aberrant elevated levels of IL-1 $\beta$ in the hippocampus may impair synaptic plasticity and memory.

Now it is well established that epigenetic regulation plays a key role in inflammatory and cognitive behavioral changes. DNA methylation is a reversible epigenetic mechanism associated with gene silencing $[13,14]$, which is catalyzed by DNA methyltransferases (DNMTs) that include DNMT1, DNMT3a, and DNMT3b. Another protein associated with DNA methylation is MeCP2, which binds to methylated cytosines and recruits histone deacetylases and other corepressors [15]. A clinical trial showed that postoperative global hypomethylation of leukocyte DNA was associated with the development of early POCD [16]. Importantly, by means of functional genomics analysis, a study described the mRNA expression profiles of various genes involved in the neuroinflammatory response in the brains of subjects with late-onset Alzheimer Disease, only IL-1 $\beta$ shows a pattern compatible with the expected relation of "Iow DNA methylation / high mRNA expression" [17]. In addition, novel findings indicate that aged mice have decreased methylation of the IL-1 $\beta$ gene promoter in microglia isolated from aged mice following systemic LPS that is associated with increased IL-1 $\beta$ mRNA, intracellular IL-1 $\beta$ production, as well as prolonged sickness behavior [18]. Although DNA methylation is involved in multiple aspects of IL-1 $\beta$ and memory, the mechanism by which DNA methylation and IL-1 $\beta$ participate in postoperative cognitive dysfunction remains unclear.

Consequently, we used exploratory laparotomy animal model to investigate the role of DNA methylation in the regulation of IL-1 $\beta$ expression and the occurrence of POCD. Our study demonstrated that surgery impaired memory formation in aged mice but not in adult mice, which was correlated with the decreased level of DNA methylation in microglia, increased expression of IL-1 $\beta$, decreased expressions of DNMT3a, DNMT3b and MeCP2 in dorsal hippocampus. The suppression of IL-1 $\beta$ in dorsal hippocampal prevented surgery-induced cognitive decline and synaptic plasticity dysfunction in aged mice.

\section{Materials And Methods}

\section{Animals}

C57BL/6J male mice (3 m, weighing 21-25 g and $18 \mathrm{~m}$, weighing 28-32 g) were obtained from animal center of Xuzhou Medical University. The animals were acclimatized for 7 days before the experiments and were group housed with the same cage mates throughout the acclimation and experiment. All the 
mice were housed under standard conditions with five mice per cage and were kept in a room $\left(22-25^{\circ} \mathrm{C}\right.$, 40-60\% humidity) maintained on a $12 \mathrm{~h} / 12 \mathrm{~h}$ dark / light cycle with access to food and water ad libitum. All experiments were approved by the Animal Care and Use Committee of Xuzhou Medical University and in accordance with the Use of Laboratory Animals and the requirements of the Animal Ethics Committee of Xuzhou Medical University, Jiangsu, China.

\section{POCD mouse model}

Exploratory laparotomy procedure was performed under isoflurane (RWD lifescience, 20052802, China) anesthesia to establish the POCD model as described in other studies [19, 20]. The 3-month and 18month mice were randomly divided into five groups: the sham group (sham), the Isoflurane group (Iso), the 1 day after surgery group (1d), the 3 day after surgery group (3d), the 7 day after surgery group (7d). The animals from the sham group remained in a chamber filled with $100 \%$ oxygen without any anesthesia / surgery procedure. For the Iso group, mice received $5 \%$ isoflurane for anesthesia induction followed by $1.4-2 \%$ isoflurane for maintenance $20 \mathrm{~min}$ without surgery procedure. For the surgery group, mice were received $5 \%$ isoflurane for anesthesia induction followed by $1.4-2 \%$ isoflurane for $20 \mathrm{~min}$. Next, approximately $1-\mathrm{cm}$ longitudinal midline incision was made to enter the abdominal cavity through the skin, abdominal muscles, and peritoneum. Then the $5 \mathrm{~cm}$ small intestine were pulled out of the abdominal cavity and gently rubbed for 30 seconds. Finally, sterile $4-0$ chromic gut sutures were used to suture the incision layer by layer. The operation process of each mouse lasted about 20 minutes, during which the mouse body temperature was monitored and kept between 36 and $37^{\circ} \mathrm{C}$ by a heating pad. Simultaneously the operator should monitor the concentration of isoflurane and oxygen flow, keep the mouse mouth, nose, and limbs rosy, and maintain a breathing rate of $70-80$ breaths $/ \mathrm{min}$. After the mice recovered from anesthesia/surgery, they were returned to their home cages. Compound lidocaine cream ( $2.5 \%$ lidocaine and $2.5 \%$ prilocaine) was locally applied to treat postoperative pain.

\section{Open field test (OFT)}

An open-field apparatus was positioned in a lit dimly room and consisted of a black Plexiglas chamber with a white floor $(35 \mathrm{~cm} \times 23 \mathrm{~cm} \times 23 \mathrm{~cm})$. OFT was used to measure the locomotor activity of the mice at different time points, as we described previously [20]. Briefly, the mice were individually placed into the center of the apparatus and were allow to explore the environment for $5 \mathrm{~min}$ freely, with the total distance travelled of the mice automatically recorded by ANY-maze software (ANY-maze, Stoelting Co., IL, USA). The installation was wiped with $75 \%$ ethanol after each test to avoid olfactory cues (such as the animal scent, stool, and urine, etc.).

\section{Object location and object recognition memory tasks (OLM and ORM)}

Novel object test apparatus was adjusted according to the described by Annie Vogel-Ciernia [21-26]. Novel object test was performed using a $35 \times 23 \mathrm{~cm}$ open arena with 23-cm-high walls. For habituation, we transported the mouse to the chamber and lower it into the bottom, then we turned hand gently so the mouse could step out of our hand into the chamber, and allowed the mouse to explore for 30 min freely. 
On training session, mice were exposed to two familiar objects and allowed to explore for $15 \mathrm{~min}$, then the animals were returned to the cage. 2 hours after training session, for object location memory (OLM), one of the two familiar objects was moved to a new location. For object recognition memory (ORM), the object locations remained constant but one of the objects was replaced with a new item. After that, mice could explore the area for 10 min freely. Exploration was scored when the mouse head oriented toward the object and came within $1 \mathrm{~cm}$ or when the nose touched the object. preference for the novel item was expressed as a discrimination index $\mathrm{DI}=$ ( $\mathrm{t}$ novel $-\mathrm{t}$ familiar) / ( $\mathrm{t}$ novel $+\mathrm{t}$ familiar). Mice that explored both objects for less than $2 \mathrm{~s}$ during testing or $3 \mathrm{~s}$ during training were removed from further analysis. Mice that showed a preference for one object during training ( $\mathrm{DI}> \pm 0.2)$ were also removed.

\section{Y maze test}

The maze consisted of three opaque arms $(8 \times 30 \times 15 \mathrm{~cm}$, width $\times$ length $\times$ height $)$ that orientated at $120^{\circ}$ angles from each other. mice were handled for $2 \mathrm{~min} /$ day for 4 days. For spatial reference memory, mice could explore the maze with the novel arm blocked for 15 min during training. After a 2-h interval, the mouse is placed back into the maze with the blockage removed, the time spent on the novel arm were recorded. For spontaneous alternation, mice explore the maze for 15 min during training. After a 2-h interval, Let the mouse explore the maze undisturbed for $8 \mathrm{~min}$, simultaneously recorded the number of all arm entries and alternations. An alternation is defined as consecutive entries into all three arms. Calculate the percent (\%) alternation using the following formula: Alternation $\%=$ Number of alternations / (total number of arm entries - 2) $\times 100$ [27].

\section{Western blot}

Western blotting was performed as we described previously [28]. Briefly, total protein and nuclear protein were extracted with radioimmunoprecipitation assay buffer (RIPA, Beyotime, P0013B, China) containing protease inhibitor cocktail (Glpbio, GK10014, USA).and ProteoExtract ${ }^{\circledR}$ Subcellular Proteome Extraction Kit (Millipore, 539790, Germany). SDS-PAGE was used to separate the proteins, which were subsequently transferred to PVDF membranes (GE Healthcare, A29562259, USA). The membrane was incubated with the following primary antibodies: anti-NF-KB P65 (1:1000; 8242P; CST, USA), anti-lba1 (1:1000; ab178846; Abcam, UK), anti-GFAP (1:1000; ab53554; Abcam, UK), anti-PSD 95 (1:1000; p246; Sigma, USA), antiSynaptophysin (1:1000; 5461S; CST, USA), anti-BDNF (1:1000; ab108319; Abcam, UK), anti-DNMT3a (1:1000; 2160S; CST, USA), anti-DNMT3b (1:1000; ab2851; Abcam, UK), anti-MeCP2 (1:1000; 3456T; CST, USA), anti-PCNA (1:1000; ab2426; Abcam, UK), anti-GAPDH (1:1000; 10494-1; Proteintech, USA) and $\beta$ actin (1:1000; bsm-33036M; Bioss, China) at 4。C overnight. The membranes were incubated with HRPconjugated secondary antibodies (1:1000; Beyotime, China) and an ECL detection system (Beyotime) and the Image $\mathrm{J}$ software were used to quantify the protein bands. The raw image files of the western blots were shown in the supplementary information [Additional file 1].

\section{Enzyme-linked immunosorbent assay (ELISA)}

Dorsal hippocampal homogenate was obtained on days 1, 3,7 after surgery and day 1 after isoflurane centrifuged at $12000 \mathrm{~g}$ at $4^{\circ} \mathrm{C}$ for 15 min to collect the supernatant. IL-1 $\beta$ (ABclonal, RK00006, USA) were 
measured according to the manufacturer's protocols. The optical density (OD) at $450 \mathrm{~nm}, 630 \mathrm{~nm}$ was obtained with an ELISA plate reader (Multiskan GO, Thermo Scientific, USA).

\section{Quantitative real-time reverse transcription PCR}

Total RNA was extracted from the dorsal hippocampus using a TaKaRa MiniBEST Universal RNA Extraction Kit (Takara, 9767, China) according to the manufacturer's protocol. cDNA was synthesized from 500 ng of RNA with PrimeScript ${ }^{\mathrm{TM}}$ RT Master Mix (Perfect Real Time) (Takara, RR036A, China), and then the real-time transcription PCRs were performed in triplicate according to the kit protocol of TB Green ${ }^{\circledR}$ Premix Ex Taq ${ }^{\text {TM }}$ (Tli RNaseH Plus) (Takara, RR420A, China) with the following primers: IL-1 $\beta$, F: 5'-CCTTGTGCAAGTGTCTGAAG - 3' and R: 5'- GGGCTTGGAAGCAATCCTTA - 3'; DNMT3a, F: 5'CTGGTGATTGGAGGCAGTCCATGCA-3' and R: 5'- TAGCTGAGGCTGTCTGCATCGGACA-3'; DNMT3b, F: 5'GGATGTTCGAGAATGTTGTGGCC-3' and R: 5'- CAGGTCAGACCTCTCTGGTGACAAG-3'; MeCP2, F: 5'GGTAAAACCCGTCCGGAAAATG-3' and R: 5'- TTCAGTGGCTTGTCTCTGAG-3'; GAPDH, F: 5'TGAAGGTCGGAGTCAACGGATTTGGT-3' and R: 5'-CATGTGGGCCATGAGGTCCACCAC-3'. The relative amount of gene expression for each target gene was determined by the $2^{-\triangle \triangle C T}$ method and expressed as the fold-change compared with a control.

\section{Immunofluorescence staining}

Mice were perfused transcardially via the left ventricle with $0.9 \%$ saline followed by $4 \%$ paraformaldehyde in $0.1 \mathrm{M}$ phosphate buffer ( $\mathrm{pH} 7.4)$. The brain tissues were harvested and postfixed in $4 \%$ paraformaldehyde overnight and dehydrated in 30\% sucrose as we reported before [29]. Sections (35 $\mu \mathrm{m}$ thick) were sliced with a freezing microtome (Leica CM1950, Germany). The brain tissue was blocked with $10 \%$ normal donkey serum in PBST for $1 \mathrm{~h}$ at room temperature and then incubated with the primary antibody for Iba1 (1:200, 019-19741, FUJIFILM Wako Pure Chemical Corporation, Japan), GFAP (1:200, 3670S, CST, USA), c-Fos (1:200, 226003, SYSY, Germany), Neuronal Nuclei (1:200, MAB377, Millipore, USA) in a cold room at $4^{\circ} \mathrm{C}$ overnight. The brain tissue was incubated with donkey anti-rabbit Alexa 594 (1:400, A21207, Invitrogen, USA) and donkey anti-mouse Alexa 488 (1:400, A32766, Invitrogen, USA) as the secondary antibody at room temperature in the dark for $2 \mathrm{~h}$. Then, the sections were mounted with DAPI Fluoromount-G (Southern Biotech, USA). The fluorescence intensity was visualized under FV-1000 confocal fluorescence microscope (Olympus, Japan). The fluorescence intensities from three slides (three visual fields per slide) were averaged for each animal [30].

\section{Golgi-Cox staining and dendritic spine counting}

Golgi-Cox impregnation was one of the effective methods to study the morphology of neurons and visualize synaptic structural plasticity [31]. The FD Rapid GolgiStain ${ }^{\text {TM }}$ Kit (FD Neurotechnologies, PK401, Columbia) was employed according to the manufacturer's instructions. Briefly, mice were deeply anesthetized by isoflurane and rapidly sacrificed. The brains were taken out as quickly as possible, washed with double-distilled water, immersed in impregnation solution, which was a mixture of solutions $A$ and $B$, and stored in the dark at room temperature for 14 days. Next, the samples were transferred to solution $\mathrm{C}$ and store at $4^{\circ} \mathrm{C}$ protected from light for at least 72 hours. Finally, the brains were sliced at a 
thickness of $150 \mu \mathrm{m}$ with oscillating tissue slicers (chamber temperature $-22^{\circ} \mathrm{C}$ ), stained and then mounted on gelatin-coated slides. After alcohol dehydration, the tissue sections were cleared in xylene and cover slipped. The dendrites from hippocampal neurons in CA1 region were captured with a confocal microscope ( $\times 100$ oil objective). Dendritic spine density was detected along CA1 secondary dendrites starting from their point of origin on the primary dendrite, and the counting of each sample was performed by an experimenter blinded to the group.

\section{Dot blot}

Total DNA (250ng) $3 \mu$ l was diluted with incubation buffer (65.7\% ammonium acetate, $7.77 \%$ formaldehyde (37\%-40\%), $6.8 \%$ MOPS) to $9 \mu \mathrm{l}$, which was kept at $65^{\circ} \mathrm{C}$ for $5 \mathrm{~min}$, and then added $12 \mu \mathrm{l} 20$ $x$ saline sodium citrate. The above mixture $5 \mu$ l were spotted on to a Hybond- $\mathrm{N}^{+}$(GE Amersham, RPN303B, UK). DNA was hybridized to the membrane with $10 \mathrm{~min}$ incubation with UV crossing. Then the membrane was immersed in methylene blue mixed liquor $(0.02 \%$ methylene blue and $0.3 \mathrm{M}$ sodium acetate) for $5-10 \mathrm{~min}$. The membrane was then incubated with a 1:1000 dilution of $5 \mathrm{mC}$ (Active Motif, 61255 , USA) at $4^{\circ} \mathrm{C}$ overnight. After three rounds of washes with $1 \times \mathrm{PBST}$, the corresponding secondary antibody was used to incubate for $2 \mathrm{~h}$, and finally an ECL detection system (Beyotime) and image $\mathrm{J}$ was used for analysis and statistics [32].

\section{Cell cultures and treatments, Lentivirus construction and infection}

For BV2 microglia and HEK293T culture, the medium was changed every other day using a 1:1 mixture of fresh DMEM (Gibco, RNBJ5984, USA) containing 10\% foetal bovine serum (SE OU Biology, C100-900, China). The cells were kept at $37^{\circ} \mathrm{C}$ in a humidified incubator with $5 \% \mathrm{CO} 2 / 95 \%$ air and used for experiments after treatment. For lentivirus construction and infection, Firstly, Overexpression DNMT3aGFP and Empty-GFP Plasmid were constructed by JingMai (Nanjing JingMai Co., Ltd., Nanjing, China). The constructed core plasmid $(16 \mu \mathrm{g})$ and two envelope plasmids, PSPAX2 $(12 \mu \mathrm{g})$ and PMD2G $(4.8 \mu \mathrm{g})$, were co-transfected into HEK293T cells in a 6-well plate according to manufacturer instructions of Lipofectamine 6000 (Beyotime, C0526, China). Then the supernatant was collected at $48 \mathrm{~h}$ after transfection, and concentrated by using a Centricon Plus-70 filter unit (UFC910096, Millipore, USA). Lentivirus with titers $10^{8} \mathrm{TU} / \mathrm{ml}$ was used in the experiment. The assays of lentivirus in BV2 infection were performed according to previous study [33]. Briefly, $20 \mu$ lentivirus and $2 \mu$ l polybrene $(1.4 \mu \mathrm{g} / \mu \mathrm{l}$; H9268, Sigma-Aldrich, USA) were added in a 24-well plate containing $1 \times 10^{5}$ BV2 cells and DMEM without FBS. After $24 \mathrm{~h}$, the transfection medium was replaced with $500 \mu \mathrm{l}$ fresh complete medium containing $10 \%$ FBS, cells were collected at $48 \mathrm{~h}$ after culture. the above cells were divided into four groups: LPS (-) + Lenti-DNMT3a group, LPS (-) + Lenti-Empty group, LPS (+) + Lenti-DNMT3a group, LPS (+) + Lenti-Empty group. The treatment included LPS $(1 \mu \mathrm{g} / \mathrm{ml})$ or left untreated for $4 \mathrm{~h}$ [29].

\section{Microglia isolation}


Animals were anesthesia via isoflurane after treatment, and dorsal hippocampus was harvest on ice and used immediately for microglia isolation using a procedure adapted from Astrid E Cardona [34]. To ensure enough cells were recovered, dorsal hippocampus from 2 mice were pooled within a given experimental group. Samples were enzymatically digested using the Papain Dissociation System (worthington, LK003150, USA). Tissue debris was removed by passing the cell suspension through a 40mm cell strainer. After myelin removal using 30\% Percoll (VICMED, VIC1555, China), cells in phosphatebuffered saline supplemented with $0.5 \%$ BSA were incubated for 30 minutes with anti- CD11b-APC antibody ( $5 \mu \mathrm{l}, 17-0112-82$, eBioscience, China) and anti- CD45-FITC antibody (5 $\mu$ l, 11-0451-82, eBioscience, China) for flow cytometry. Isolated microglia of CD $11 b^{+} /$CD $45^{\text {low }}$ were around $1 \times 10^{6}$ cells per 2 brains and were not different between treatments.

\section{Methylated DNA immunoprecipitation (MeDIP)}

Methylated DNA immunoprecipitation was performed using a 5-methylcytosine $(5 \mathrm{mC})$ antibody $(1 \mu \mathrm{g} /$ reaction, A-1014, Epigentek, USA) as described previously with minor modifications [35, 36]. Genomic DNA was extracted by TaKaRa MiniBEST universal Genomic DNA Extraction Kit (TaKaRa, 9765, China), treated with RNase A and quantified using Nanodrop 2000, $50 \mathrm{ng} / \mathrm{ml}$ of DNA per sample were prepared using IP buffer(100 mM Tris-Hcl PH 7.40, $150 \mathrm{mM} \mathrm{Nacl,} \mathrm{0.05 \%} \mathrm{Triton-100)} \mathrm{and} \mathrm{sonicated} \mathrm{(BioruptorTM}$ UCD-200, Diagenode SA, Lige, Belgium) to 200 bp-1000 bp fragments for methylation analysis. An additional file showed the ultrasound effect in more detail [Additional file 2e]. Sonicated DNA were taken out $2000 \mathrm{ng}$, which diluted to $150 \mu \mathrm{l}$ with IP buffer, then incubated and rotated at $4^{\circ} \mathrm{C}$ overnight with $2 \mu \mathrm{l}$ $5 \mathrm{mC}$ antibody and Negative control IgG, The next day, methylated DNA was collected with protein $\mathrm{G}$ magnetic beads (New England BioLabs, S1430S, USA), washed with IP buffer, extracted for $2 \mathrm{~h}$ at $60^{\circ}$ with proteinase $\mathrm{K}$ in TE buffer with $1 \%$ SDS, and purified with TaKaRa MiniBEST DNA Fragment Purification Ki (TaKaRa, 9761, Japan). Methylation at selected DNA regions was assayed via qPCR according to the kit protocol of TB Green ${ }^{\circledR}$ Premix Ex Taq ${ }^{\text {TM }}$ (Tli RNaseH Plus) (Takara, RR420A, China) on a quantstudio 7 flex real-time PCR system (Thermo Fisher Scientific, USA) at $95^{\circ} \mathrm{C}$ for $1 \mathrm{~min}$, followed by $45 \mathrm{cycles}$ of $95^{\circ} \mathrm{C}$ for $30 \mathrm{~s}$ and $58^{\circ} \mathrm{C}$ for $20 \mathrm{~s}$, and then incubation at $72^{\circ} \mathrm{C}$ for $10 \mathrm{~s}$ followed by real-time melt analysis to verify product specificity. At the same time, the agarose gel electrophoresis was used to verify product specificity, and the raw image was saw in the additional $2 \mathrm{e}$. the primers as followed: IL-1 $\beta$, F: 5'- AGCTCCCTCAGCTTAAGCAC- 3' and R: 5'- CACATTCGCAAGTGTGTCAT - 3'; GAPDH, F: 5'AACGACCCCTTCATTGAC-3' and R: 5'-TCCACGACATACTCAGCAC-3'. Ct values for IP samples were normalized to unprocessed (input) DNA. GAPDH, which did not change across samples, was used as an internal normalization control.

\section{Methylation-specific real-time PCR (MSP)}

Sodium bisulfite modification and methylation-specific real-time PCR was used to analyze DNA methylation changes in promoter region. Bisulfite modification of genomic DNA converts unmethylated cytosine residues into uracil residues. In contrast, the methylated cytosine residues will remain unchanged. Sodium bisulfite modification of DNA was performed using the CpGenome ${ }^{\text {TM }}$ Turbo Bisulfite Modification Kit (Millipore, 2906402, USA) according to the manufacturer's protocol. PCR amplification 
was carried out according to Episcope MSP Kit (TaKaRa, R100A, China) instructions. Primer sets targeted a methylated and unmethylated CG dinucleotide in DNA associated with the promoter region of IL-1 $\beta$ or unmethylated $\beta$-tubulin-4 as a reference gene as previously published [37] and the primers as followed: IL$1 \beta$ methylated, F: 5'- TTTTAGTTTAAGTATAAGGAGGCGA- 3' and R: 5'- ACACATTCGCAAATATATCATCGTA - 3'; IL-1 $\beta$ unmethylated, F: 5'- TTTTAGTTTAAGTATAAGGAGGTGA- 3' and R: 5'-

AACACATTCACAAATATATCATCATA - 3'; $\beta$-tubulin-4 unmethylated, F: 5'-

GGAGAgTAATATGAATGATTTGGTG-3' and R: 5'- CATCTCCAACTTTCCCTAACCTACTTAA-3'. Product specificity was determined by curve analysis. For the MSP data, a methylation index was calculated by dividing the fold change value for the methylated primer set by the fold change value for the unmethylated primer as previously described [38, 39].

\section{Intracerebroventricular cannulation and administration of recombinant IL-1ra}

Interleukin-1 receptor antagonist (IL-1 ra) functions as a competitive inhibitor of IL-1 a and IL-1 $\beta$ binding to the IL-1 type 1 receptor with an affinity equal to IL-1 $\beta$ without any agonist activity [40]. it was reported that intracisterna magna administration of IL-1 ra would effectively block action of IL-1 $\beta$ within the CNS, including the hippocampus [41]. To confirm the impact of blocking central action of IL-1 $\beta$ before surgery, 18- month mice were randomly divided into four groups: sham + veh group $\square$ sham + IL-1 ra group $\otimes 1 \mathrm{~d}+\mathrm{veh}$ group $₫ 1 \mathrm{~d}+\mathrm{IL}-1$ ra group. Mice were prepared with an intracerebroventricular cannula as described previously[42, 43]. In brief, mice were anesthetized with an intraperitoneal injection of Avertin (isoamyl alcohol, $250 \mathrm{mg} / \mathrm{kg}$ ). They were positioned in a stereotaxic frame so that the plane formed by the frontal and parietal bones was parallel to horizontal zero. A cannula (O.D 0.41) (RWD lifescience, China) was placed in the left lateral cerebral ventricle according to predetermined coordinates (AP: $-0.5 \mathrm{~mm}$; ML: 1.0 $\mathrm{mm}$; DV: $-2.1 \mathrm{~mm}$ ). Mice were provided a minimum of 5 days to recover before any treatment or behavioral test. To verify entry into the lateral cerebral ventricle, $\sim 2 \mu$ of clear CSF was drawn and gently pushed back in and a $3 \mu$ l total volume of IL-1 ra (4 $\mu \mathrm{g}, 480-R M / C F$, R\&D Systems, Minneapolis, MN) was administered 30 min prior to laparotomy or sham. An equal volume of sterile saline was injected into vehicle animals.

\section{Sequenom MassARRAY® Methylation of IL-1 $\beta$ promoter}

The specific process was completed by CaptitalBio technology and the specific steps were provided by it. Used Sequenom's Epidesigner (http://www.epidesigner.com) to design primers. Usually, The PCR primers should be designed to yield a product within a 200-600 bp range. After the primer designed, it would be synthesized by the biological company. Used QIAamp DNA Mini Kit (QIAGEN) and other kits to extract DNA from the dorsal hippocampus. The DNA was quantified with a spectrophotometer, and $100 \mathrm{ng}$ of DNA was taken and checked by $0.8 \%$ agarose gel electrophoresis. Then adjusted the concentration of qualified DNA to $75 \mathrm{ng} / \mu \mathrm{l}$, transferred it to a 384-well plate, and stored it at $-20^{\circ} \mathrm{C}$ for later use. The following steps were completed with various types of kits: DNA sample sulfite treatment (EZ DNA Methylation-Gold Kit, ZYMO), PCR amplification (PCR Accessory Set, SEQUENOM), alkaline phosphatase treatment (SAP) (MassCLEAVE Kit, SEQUENOM), in vitro transcription and RNase digestion (MassCLEAVE 
Kit, SEQUENOM), purification, spotting and mass spectrometry (Spectro CHIP® Arrays and Clean Resin), Referred to the kit instructions for the specific process.

\section{Data analysis and statistics}

Data are presented as the mean \pm S.E.M. and were analyzed with GraphPad Prism 8.0 (GraphPad Software, Inc.). The statistical compassion for two groups were made with Independent-Samples $\mathrm{T}$ Test. For multiple compassion were made with one-way ANOVAs followed by between-group comparisons using the Bonferrioni. Differences were considered significant when $P<0.05$.

\section{Results}

\section{Surgery but not anesthesia impaired hippocampus- dependent cognition in aged mice}

We first tested whether surgery or anesthesia only could affect cognition with aged (18 m) and adult (3 m) mice (Fig. 1a). In the open-field test, the total distance travelled showed no significant differences among all groups (aged: $\mathrm{F}(3,32)=1.383, P=0.2657$, adult: $\mathrm{F}(3,32)=1.593, P=0.2103$, Fig. $1 \mathrm{~b})$ which means the locomotor activity was unaffected. Next, we investigated the effects of surgery on learning and memory. As shown in novel object test, there were no significant preference in all groups during training [Additional file 2c]. During testing, surgery induced object-place recognition deficits in aged mice $1 \mathrm{~d}$ after surgery $(\mathrm{F}(3,32)=7.934, \mathrm{P}=0.0004$, Fig. $1 \mathrm{~d})$. Object recognition memory was normal $(F(3,32)=$ $0.7731, P=0.5176$, Fig. 1c). Whereas adult mice showed no significant differences among all groups in $\operatorname{OLM}(\mathrm{F}(3,32)=0.9032, P=0.4504$, Fig. $1 \mathrm{~d})$, and $\operatorname{ORM}(\mathrm{F}(3,32)=0.3802, P=0.7679$, Fig. $1 \mathrm{c})$. In addition, in $Y$ maze test, compared with the sham group, the spontaneous alternation index $(F(3,32)=13.07, P<$ 0.0001 , Fig. 1e) and the time in the novel $\operatorname{arm}(\mathrm{F}(3,32)=9.374, P=0.0001$, Fig. 1f) of aged mice were decreased in $1 \mathrm{~d}$ group, but not in $3 \mathrm{~d}$ and $7 \mathrm{~d}$ groups. While adult mice showed no significant differences among all groups $(\mathrm{F}(3,32)=0.8422, P=0.4809$, Fig. 1e; $\mathrm{F}(3,32)=1.649, P=0.1976$, Fig. $1 \mathrm{f})$.

In the present model, anesthesia and surgery often occur concurrently, so we explored the effect of isoflurane anesthesia only on the cognitive function of adult and aged mice. In OLM, ORM, and Y maze, compared with the control group, the cognitive function of adult and aged mice did not change $1 \mathrm{~d}$ after isoflurane anesthesia alone (aged: $\mathrm{t}=0.2300, P=0.8210$, adult: $\mathrm{t}=0.6328, P=0.5358$, Fig. $1 \mathrm{~g}$; aged: $\mathrm{t}=$ 1.088, $P=0.0 .2926$, adult: $\mathrm{t}=0.6767, P=0.5083$, Fig. 1 h; aged: $\mathrm{t}=1.529, P=0.1458$, adult: $\mathrm{t}=0.3644, P=$ 0.7203, Fig. 1i; aged: $\mathrm{t}=0.3268, P=0.7481$, adult: $\mathrm{t}=1.034, \mathrm{P}=0.3166$, Fig. $1 \mathrm{j})$. These results suggested that surgical trauma during the perioperative period, rather than anesthesia, may play a more important role in POCD. Surgery induced hippocampus-dependent cognitive decline in aged mice.

\section{The microglia in the dorsal hippocampus was activated after surgery}


Since IL-1 $\beta$ mediates the inflammatory response and affects hippocampal memory functions [44], we focused on the neuroinflammation induced by IL-1 $\beta$ in the present model. Our data showed that the mRNA expressions of IL-1 $\beta(F(4,25)=6.836, P=0.0007$, Fig. $2 a)$ as well as the protein expressions of IL$1 \beta(F(4,15)=7.163, P=0.002$, Fig. $2 b)$ in the dorsal hippocampus of the $1 \mathrm{~d}$ group were higher than those in the sham group in aged mice, while adult mice showed no significant differences among all groups ( $F$ $(4,35)=0.3623, P=0.8337$, Fig. 2a; F $(4,15)=1.558, P=0.2363$, Fig. $2 b)$. Anesthetics alone produced no change of IL-1 $\beta$ levels observed in $1 \mathrm{~d}$ group and sham group. NF-KB is a transcriptional factor that plays a crucial role in the expression of proinflammatory cytokines in microglia. After translocating into the nucleus, it upregulates the expression of IL-1 $\beta$ [45]. We next evaluated the expression level of p65, a subunit of NF-KB, in the dorsal hippocampal cell nucleus and found that the level of p65 were upregulated $1 \mathrm{~d}$ after surgery as expected in aged mice $(\mathrm{t}=5.029, P=0.0125$, Fig. $2 \mathrm{c})$.

IL-1 $\beta$ expression has been documented in neurons, microglia and astrocytes [46-51]. Thus we assessed the changes in microglia and astrocytes. Immunofluorescence staining showed that Iba1 expression was increased in the CA1 region of the dorsal hippocampus on postoperative day 1 in aged mice $(t=5.565, P$ $=0.0014$, Fig. $2 \mathrm{e}$ ). Correspondingly, immunoblotting for Iba1 revealed a visible increase in Iba1 expression in the CA1 region of the dorsal hippocampus of aged mice on postoperative day $1(t=2.537, P=0.0349$, Fig. $2 \mathrm{~g})$. More interestingly, the same change was also found in adult mice $(\mathrm{t}=15.17, P<0.0001$, Fig. $2 \mathrm{e}, \mathrm{t}$ $=3.012, P=0.0131$, Fig. $2 \mathrm{~g}$ ). Then we assessed the change in astrocytes of adult and aged mice, our data showed that proportional GFAP area and the expression of GFAP showed no significant change in the $1 \mathrm{~d}$ group compared with the sham group (aged: $\mathrm{t}=1.486, P=0.1879$, adult: $\mathrm{t}=1.319, P=0.2352$, Fig. 2f; aged: $\mathrm{t}=0.3824, P=0.9241$, adult: $\mathrm{t}=0.4406, P=0.6712$, Fig. $2 \mathrm{~h}$ ). These results demonstrated that the microglia instead of astrocytes in dorsal hippocampus were activated after surgery.

\section{Epigenetic regulators relevant to DNA methylation `changed in microglia of dorsal hippocampus induced by surgery in aged mice.}

To gain a broader view of the role of epigenetic regulators in neuroinflammation, the mRNA expressions as well as the protein expressions for several enzymes that participate in DNA methylation were measured in dorsal hippocampus from aged mice $1 \mathrm{~d}$ after surgery. No changes were found in mRNA and protein expressions of DNMT3a, DNMT3b, MeCP2 (DNMT3a: $\mathrm{t}=0.001376, P=0.9989$, DNMT3b: $\mathrm{t}=$ 0.1285, $P=0.9009$, MeCP2: $\mathrm{t}=1.714, P=0.1248$, Fig. 3a; DNMT3a: $\mathrm{t}=2.019, P=0.0781$, DNMT3b: $\mathrm{t}=$ 1.497, $P=0.1728$, MeCP2: $\mathrm{t}=0.1637, P=0.8741$, Fig. $3 \mathrm{~b})$.

It was reported that DNA methyltransferases (DNMT3a, DNMT3b) add a methyl group to the 5-carbon of cytosine to form 5-methylcytosine $(5 \mathrm{mC})$, particularly for cytosine nucleotides that are located next to a guanine nucleotide as a stable repressive regulator of promoter activity [52]. To this end, we assessed the level of $5 \mathrm{mC}$ by dot blot. Our results showed that the global $5 \mathrm{mC}$ of dorsal hippocampus showed no significant change in the $1 \mathrm{~d}$ group compared with the sham group $(\mathrm{t}=0.06296, P=0.9528$, Fig. $3 \mathrm{c})$. These results indicated that the global level of DNA methylation in dorsal hippocampus remained unchanged. As the inflammatory factors are mainly released from microglia. Next we examined the gene 
expression regulated by DNA methylation in microglia. The dorsal hippocampus cells from aged mice after surgery or sham were isolated using CD11b-APC and CD45-FITC antibodies by flow cytometry. These cells identified as $C D 11 b^{+}$and $C D 45^{\text {low }}$, which were thought to be predominantly microglia (Fig. 3d). Then mRNA levels for several enzymes that participated in DNA methylation were measured. Of consequence, the mRNA levels of DNMT3a, DNMT3b and MeCP2 were decreased in aged mice at $1 \mathrm{~d}$ after surgery (DNMT3a: $\mathrm{t}=32.08, P<0.0001$, DNMT3b: $\mathrm{t}=6.409, \mathrm{P}=0.0007, \mathrm{MeCP} 2 \mathrm{t}=8.632, P=0.0001$, Fig. 3e). These results showed that epigenetic regulators (DNMT3a, DNMT3b and MeCP2) changed in microglia of dorsal hippocampus induced by surgery in aged mice.

\section{The IL-1 $\beta$ promoter DNA methylation was decreased induced by surgery in aged mice}

As the expression of NF-kB P65 was increased in aged mice $1 \mathrm{~d}$ after surgery. Simultaneously other studies have reported that NF-kB binding activity might play a role in demethylation of the IL-1 $\beta$ promoter [52]. So, the site of methylation investigated in this study was adjacent to a canonical NF-kB-binding site (CpG sites $-229 \mathrm{bp}$ and $-215 \mathrm{bp}$ to translation start site in the IL-1 $\beta$ promoter). As expected, the levels of DNA methylation at above two sites were reduced by surgery in aged mice (MSP: $\mathrm{t}=2.661, P=0.0375$, MeDIP: $\mathrm{t}=3.753, P=0.0095$, Fig. 4a). In contrast, Most CpGs, except above two sites, were highly methylated and not affected by surgery which we examined $>10 \mathrm{CpGs}$ for the region -1439 and 760 to the ATG translation start site (Fig. 4b).

To demonstrate whether DNA methylation played a direct role in IL-1 $\beta$ expression, the BV2 immortalized murine microglial cell line were infected with lentiviral vectors expressing DNMT3a tagged with green fluorescent protein (GFP) (Lenti-DNMT3a-GFP) or vacant vector (Lenti-empty-GFP). Then the cultures were harvested after treatment with LPS. BV2 were well infected with Lenti-GFP (Fig. 4c), and the morphology did not change. We first detected the expression of DNMT3a, which was significantly reduced by LPS ( $\mathrm{t}=3.846, P=0.0049$, Fig. $4 \mathrm{~d})$. After infection with Lenti-DNMT3a, the expression of DNMT3a was rescued compared to the Lenti-Empty + LPS $(-)$ group $(\mathrm{t}=3.501, P=0.0081$, Fig. $4 \mathrm{~d})$. Then, we examined the effects of overexpression of DNMT3a on IL-1 $\beta$ expression and DNA methylation of IL$1 \beta$. The increased expression of IL-1 $\beta(F(3,12)=12.00, P=0.0006$, Fig. $4 \mathrm{e})$ and the decreased DNA methylation of IL-1 $\beta(F(3,8)=10.16, P=0.0042$, Fig. $4 f)$ induced by LPS was rescued by Lenti-DNMT3a as well. So, these results showed that the IL-1 $\beta$ promoter DNA methylation was decreased induced by surgery in aged mice. Overexpression of DNMT3a to reverse methylation of IL-1 $\beta$ could rescue neuroinflammation induced by LPS.

\section{IL-1 impaired synaptic plasticity in the dorsal hippocampus of aged mice in POCD model}

To specifically confirm the role of IL-1 $\beta$ in memory deficits, IL-1 ra was injected bilaterally into lateral ventricle to suppress the expression of IL-1 $\beta$ in dorsal hippocampus (Fig. 5a). The level of IL-1 $\beta$ in the dorsal hippocampus of aged mice was inhibited by lateral cerebral ventricle administration of IL-1ra just before surgery $(F(3,12)=11.30, P=0.0008$, Fig. $5 b)$. The Golgi staining results showed that the IL-1ra 
could reverse the reduced spine density in the dorsal hippocampal CA1 region $(F(3,12)=4.841, P=$ 0.0197, Fig. 5d). Regarding synaptic functional plasticity, various genes are related to IL-1 $\beta$ and synaptic functional, such as BDNF, PSD95, and synaptophysin, which are involved in learning and memory. We found that the protein expressions of hippocampal BDNF, PSD95 and synaptophysin were significantly decreased in the surgery-treated mice, while IL-1 ra could reverse this change similarly $(\mathrm{F}(3,16)=4.045, P$ $=0.0256$, Fig. $5 f, F(3,16)=4.582, P=0.0169$, Fig. $5 g, F(3,12)=4.877, P=0.0192$, Fig. 5h). Furthermore, the number of $\mathrm{c}^{-\mathrm{Fos}^{+}}$neuron in the CA1 region of aged mice was decreased on postoperative day 1 , but IL-1ra significantly attenuated the loss of $\mathrm{c}-\mathrm{Fos}^{+}$neuron $(\mathrm{F}(3,16)=17.53, P<0.0001$, Fig. 5i). These results indicated that IL-1 $\beta$ impaired synaptic plasticity in the dorsal hippocampus of aged mice in POCD model.

\section{Inhibiting IL-1 $\beta$ in the dorsal hippocampal rescued memory deficits induced by surgery}

Next, we further investigated whether inhibiting IL-1 $\beta$ in the dorsal hippocampus of aged mice by administration of IL-1 ra bilaterally into lateral ventricle would rescue the memory deficits induced by surgery. In the open-field test, the total travelled distance showed no significant differences among all groups $(F(3,28)=1.207, P=0.3253$, Fig. $6 a)$. In the OLM task, all groups showed no significant preference in the novel objection recognition test during training [additional file 2d]. During testing, the discrimination ratio was reversed by inhibiting $\operatorname{IL}-1 \beta(F(3,28)=32.07, P<0.0001$, Fig. $6 \mathrm{~b})$. In the $Y$ maze task, Similarly the spontaneous alternation index and the time in the novel arm of aged mice was reversed by inhibiting IL-1 $\beta(F(3,28)=10.14, P=0.0001$, Fig. 6 c; $F(3,28)=6.361, P=0.0020$, Fig. $6 \mathrm{~d})$. Based on above data, the impairment of memory performance induced by surgery exposure was restored by suppressing IL-1 $\beta$.

\section{Discussion}

In the present study, we showed that aged but not adult mice exhibited hippocampus-dependent postoperative cognitive decline and increased gene expression of IL-1 $\beta$ at $1 \mathrm{~d}$ after surgery. The microglia in the dorsal hippocampus was activated and the IL-1 $\beta$ promoter DNA methylation was decreased in the aged mice. The increased expression of IL-1 $\beta$ impaired synaptic plasticity and hippocampus-dependent memory formation of aged mice in POCD model.

It was reported that object-place memory and object memory appear to be dependent on different brain regions. Object-place memory requires the hippocampus for encoding, consolidation, and retrieval [53, 54], and it is particularly sensitive to manipulations in dorsal CA1 [55], whereas object memory requires the participation of different brain regions including perirhineal cortex, insular cortex and medial prefrontal cortex [56]. The role of the hippocampus in object recognition has remained controversial [57]. Therefore, from this point, we could think that the effect of surgery on the cognitive function of aged mice mainly depended on the dorsal hippocampus. However, Impaired object-place memory and spatial 
memory were not occurred by a single use of isoflurane alone in adult and aged mice, which suggested that a single use of isoflurane alone would not induce memory deficits in patients with abdominal surgery. Previous studies have demonstrated that isoflurane exposure in aged rats lead to impaired spatial memory and neuroinflammation [58]. Maternal exposure to isoflurane impaired learning and memory of the offspring [59]. These indicated that age may be an independent susceptibility factor resulting in anaesthesia-induced cognitive impairment. However, this was not inconsistent with our results. The discrepancies among these researches exposed to isoflurane inhalation alone might result from the different dose and time. Consistent with this was that the general anesthetic may impair developing neurons and induce young adult male C57BL/ 6 mice cognitive dysfunction in a dose- and time- dependent manner $[60,61]$. We also found that LPS-impaired object recognition and fear memory were not aggravated by isoflurane in adult mice [29]. Simultaneously Silbert BS et al. also found no significant difference in the rates of POCD when comparing general anaesthesia (contained isoflurane) with spinal anaesthesia, suggesting that the surgical or procedural process itself may contribute to the development of POCD [62]. In addition, a research provided proof-of-concept evidence that inflammation increases the sensitivity of neurons to general anesthetics [63].

Accumulating evidence suggests that neuroinflammation and aged play critical roles in cognitive impairment induced by surgery [64-66]. It is reported that microglia are tuned for different types of host defense and protection, depending on the presence of available cytokines. Classical, or "M1," polarizing signals arm macrophages to elicit proinflammatory and cytotoxic mediators, whereas alternatively activated "M2" macrophages can dampen inflammation and promote tissue regeneration $[13,67,68]$. So combined with the level of IL-1 $\beta$ of aged and adult mice, we thought the microglia of adult mice could activate "M2" macrophages. Other perioperative injury factors, such as reactive oxygen species [69], imbalance of cerebral iron metabolism [70], and down regulated type 2 cannabinoid receptors [71] could also induce microglial activation and ultimately lead to postoperative neurological sequela. Another important source of IL-1 $\beta$ in CNS was astrocytes. It is reported that GFAP concentrations showed no relationship to postoperative delirium [72], which is coincidence with our results. During neuroinflammation, astrocytes undergo morphological changes that are not strictly dependent on GFAP protein level [73] and only $15 \%$ of astrocytes stain for GFAP in the mouse brain [74], thus the role of astrocytes in POCD needs to be determined by further experiments.

We further demonstrated that age and surgery trauma have the capacity to alter DNA methylation and expression levels of genes important for establishing and maintaining DNA methylation in microglial cells isolated from surgery treated mice, such as DNMT3a, DNMT3b, MeCP2. Since the isolated aged microglia were hard to survive, we chose LPS-preconditioned BV2 cells to simulate microglia.

Overexpression of DNMT3a was able to reversed the decreased methylation of the IL-1 $\beta$ promoter that coincide with increased intracellular IL-1 $\beta$ production in LPS-preconditioned BV2 cells, suggesting that DNA methylation played an important role in the expression of IL-1 $\beta$ with age and neuroinflammation. This also indicated that BV2 have the capacity to display DNA methylation patterns in a manner consistent with what was seen in freshly isolated microglia. A study using microglia isolated from LPStreated mice to explore the changes of IL-1 $\beta$ and its DNA methylation is consistent with ours [18]. Further 
study by using of transgenic inducible cre mouse models that allow for manipulation of specific floxed genes, or tagging of cell-specific nuclei/and or polysomes represent valuable research tools is needed [75].

Interestingly, we also found that global DNA methylation of dorsal hippocampus was unchanged, suggesting that perhaps DNA hypomethylation is not a global phenomenon. In fact, many researches have observed an age-related increase in the DNA methylation promoter of neuronal activity and synaptic marker genes [76, 77], and an age-related decrease in the DNA methylation promoter of immune-related genes [78]. It appears consensual that DNA methylation plays a central role in cognitive function. The manipulation of DNA methylation-related mechanisms consistently impacts memory processes [79]. Considering the current study, DNA methylation seems to regulate the expression of genes with relevant functions in neuroinflammation in brain regions critical for memory. However, several gaps in the understanding of how DNA methylation regulates IL-1 $\beta$ and microglia function still exist. For instance, it is not known how specificity is achieved, specifically how DNA methyltransferases or demethylases are targeted to specific genomic sites. Studies suggest that noncoding RNAs [80,81] or chromatin marks [82-83] may be responsible for that targeting, but these mechanisms are still far from being understood.

The site of methylation investigated in this study is adjacent to a cnonical NF-kB-binding site which is individual CpGs near the transcription start site (TSS) exhibits considerable variability in methylation for promoter regions without CpG islands [84]. Several NF-KB (p65 / RelA and cRel) consensus sequences have been revealed within the Gadd $45 \beta$ gene promoter, which is in regulation of Gadd $45 \beta$ expression and DNA demethylation in hippocampal neurons during fear memory [85]. It has provided evidence in microglia that epigenetic regulation of IL-1 $\beta$ from aged mice could be regulated by increased NF-KB binding that inhibits proper DNA methylation. Most studies show a negative correlation between DNA methylation and expression, but some recent studies show a positive association between gene expression and methylation at the gene body [36]. Our findings showed that, in aged mice, hypomethylation of IL-1 $\beta$ at specific $\mathrm{CPG}$ sites was associated with its increased expression. The above changes are also found in other models and species. The transcriptional regulation of IL-1 $\beta$ through methylation in mouse myeloid cells is remarkably consistent with findings in human normal aging and demented patients with tauopathy. They found one specific CpG site, 215 bp upstream of transcription start site (TSS), whose methylation status affects IL-1 $\beta$ transcript levels, which is consistent with our results. in humans. There are two CpGs (cg01290568 and cg15836722) within the IL-1 $\beta$ gene body near the TSS whose methylation negatively correlates with aging and dementia. This suggests selective regulation of specific CpGs at IL-1 $\beta$ gene in both mice and humans [87].

IL-1 $\beta$ is a key proinflammatory cytokine associated with age-related cognitive decline [88]. IL-1 $\beta$ exerts its biological action by binding to IL-1 receptor type 1 (IL-1RI), competing with IL-1 receptor antagonist (IL$1 \mathrm{ra})$, the endogenous inhibitor of IL-1 [40]. A growing body of evidence indicates that synaptic plasticity [89], learning and memory [9] are more vulnerable to impairment by IL-1 $\beta$ with age. The synapseassociated proteins, especially the synaptophysin and PSD95 are decreased in the hippocampus of LPSexposed mice. Galantamine not only prevents the LPS-induced reduction of synaptophysin and PSD-95, 
but also increases dendritic spine density which could prevent activation of microglia and astrocytes and improve neuroinflammation by inhibition of inflammatory signaling molecule (NF-kB p65) and cytokines (TNF- $a$, IL-1 $\beta$ and IL-6) in the hippocampus of LPS-exposed mice [90].

\section{Conclusion}

In summary, the current study indicated that DNA methylation may be an important mechanism for susceptibility to POCD in aged mice by regulating the expression of IL-1 $\beta$, which could induce synaptic plasticity dysfunction and cognitive decline (Fig. 7). Our results may provide a potential direction for further research on the relationship among DNA methylation, inflammation and POCD. The research also provides a new target for the clinical prevention of the occurrence of POCD in the elderly.

\section{Abbreviations}

POCD

Postoperative cognitive dysfunction; IL-1 $\beta$ :Interleukin (IL)-1 $\beta$; IL-1 ra:Interleukin (IL)-receptor antagonist; Iba1:Ionized calcium binding adapter molecule 1; TNF-a:Tumor necrosis factor-alpha; IL-6:Interleukin (IL)-6; OFT:Open field test; BCA:Bicinchoninic acid; ELISA:Enzyme-linked immunosorbent assay; RTPCR:Quantitave Real-time PCR; MeDIP:Methylated DNA immunoprecipitation; MSP:methylation-specific real time PCR; DNMTs:DNA methyltransferases; DAPI:4',6-diamidino-2-phenylindole; ECL:Enhanced chemiluminescence; GFAP:Glial fibrillary acidic protein; Iso:Isoflurane; LPS:Lipopolysaccharide; Syn:Synaptophysin; OLM:Object location memory; ORM:Object recognition memory; DI:Discrimination index; FBS:Foetal bovine serus.

\section{Declarations}

\section{Acknowledgments}

We are thankful for experimental support from Jiangsu Province Key Laboratory of New Drug Research and Clinical Pharmacy. Financial support from the National Natural Science Foundation of China, the Qing Lan Project of Jiangsu Province, the Natural Science Foundation of the Jiangsu Province, and the Postgraduate Research \& Practice Innovation Program of Jiangsu Province are also acknowledged.

\section{Author Contributions}

C.G. designed and supervised the research; Y.G., L.Y., X.Y., X.L., L.L., Y.Y., Y.G., Y.Y.L., L.Y., K.T., D.S.C. provided acquisition, analysis, and interpretation of data, and statistical analysis; Y.G. and L.Y. wrote the paper; C.G., Y.Y., Y.G., Y.Y.L., L.Y., K.T., D.S.C., J.R.H. and N.S. revised the paper; Z.M.Z., J.R.H. and N.S. provided technical and material support. All authors read and approved the final paper.

\section{Funding}


This work was supported by the National Nature Science Foundation Grant of China (81870852, 81471101), the Qing Lan Project of Jiangsu Province, the Education Department of Jiangsu Province (18KJA320007) and the Natural Science Foundation of the Jiangsu Province (BK20181146) to Dr. Gao, the Education Department of Jiangsu Province (17KJB320018) to M.S. Hao, the Postgraduate Research \& Practice Innovation Program of Jiangsu Province (KYCX20_2453) to Dr. X Yang, (KYCX20_2454) to Dr. L Yang, (KYCX20_2475) to M.S. Li.

\section{Data Availability Statement}

The data sets used and analyzed during the current study are available from the corresponding author on reasonable request.

\section{Ethics statement}

This study was approved by the Animal Care and Use Committee of Xuzhou Medical University in compliance with National Institutes of Health standards.

\section{Consent for publication}

Not applicable.

\section{Competing interests}

The authors declare that they have no competing interests.

\section{References}

1. Luo A, Yan J, Tang X, Zhao Y, Zhou B, Li S. Postoperative cognitive dysfunction in the aged: the collision of neuroinflammaging with perioperative neuroinflammation. Inflammopharmacology. 2019;27:27-37.

2. Johnson T, Monk T, Rasmussen LS, Abildstrom H, Houx P, Korttila K, et al. ISPOCD2 Investigators. Postoperative cognitive dysfunction in middle-aged patients. Anesthesiology. 2002;96:1351-7.

3. Monk TG, Weldon BC, Garvan CW, Dede DE, van der Aa MT, Heilman KM, et al. Predictors of cognitive dysfunction after major noncardiac surgery. Anesthesiology. 2008;108:18-30.

4. Meybohm P, Renner J, Broch O, Caliebe D, Albrecht M, Cremer J, et al. Postoperative neurocognitive dysfunction in patients undergoing cardiac surgery after remote ischemic preconditioning: a doubleblind randomized controlled pilot study. PLoS One. 2013;8:e64743.

5. Li Z, Liu F, Ma H, White PF, Yumul R, Jiang Y, et al. Age exacerbates surgery-induced cognitive impairment and neuroinflammation in Sprague-Dawley rats: the role of IL-4. Brain Res. 2017;1665:65-73.

6. Le Y, Liu S, Peng M, Tan C, Liao Q, Duan K, et al. Aging differentially affects the loss of neuronal dendritic spine, neuroinflammation and memory impairment at rats after surgery. PLoS One. 
2014;9:e106837.

7. Wang Z, Meng S, Cao L, Chen Y, Zuo Z, Peng S. Critical role of NLRP3-caspase-1 pathway in agedependent isoflurane-induced microglial inflammatory response and cognitive impairment. $J$ Neuroinflammation. 2018;15:109.

8. Hovens IB, Schoemaker RG, van der Zee EA, Heineman E, Nyakas C, van Leeuwen BL. Surgeryinduced behavioral changes in aged rats. Exp Gerontol. 2013;48:1204-11.

9. Patterson SL. Immune dysregulation and codysregulationrability in the aging brain: Interactions of microglia, IL-1beta, BDNF and synaptic plasticity. Neuropharmacology. 2015;96:11-8.

10. Salter MW, Stevens B. Microglia emerge as central players in brain disease. Nat Med. 2017;23:101827.

11. Smith DM, Mizumori SJ. Hippocampal place cells, context, and episodic memory. Hippocampus. 2006;16:716-29.

12. Squire LR, Stark CE, Clark RE. The medial temporal lobe. Annu Rev Neurosci. 2004;27:279-306.

13. Petralla S, De Chirico F, Miti A, Tartagni O, Massenzio F, Poeta E, et al. Epigenetics and Communication Mechanisms in Microglia Activation with a View on Technological Approaches. Biomolecules. 2021;11:306.

14. Cheray M, Joseph B. Epigenetics Control Microglia Plasticity. Front Cell Neurosci. 2018;12:243.

15. Dor Y, Cedar H. Principles of DNA methylation and their implications for biology and medicine. Lancet. 2018;392:777-86.

16. Li H, Wu TT, Tang L, Liu Q, Mao XZ, Xu JM, et al. Association of global DNA hypomethylation with post-operative cognitive dysfunction in elderly patients undergoing hip surgery. Acta Anaesthesiol Scand. 2020;64:354-60.

17. Nicolia V, Cavallaro RA, Lopez-Gonzalez I, Maccarrone M, Scarpa S, Ferrer I, et al. DNA Methylation Profiles of Selected Pro-Inflammatory Cytokines in Alzheimer Disease. J Neuropathol Exp Neurol. 2017;76:27-31.

18. Matt SM, Lawson MA, Johnson RW. Aging and peripheral lipopolysaccharide can modulate epigenetic regulators and decrease IL-1 beta promoter DNA methylation in microglia. Neurobiol Aging. 2016;47:1-9.

19. Peng M, Zhang C, Dong Y, Zhang Y, Nakazawa H, Kaneki M, et al. Battery of behavioral tests in mice to study postoperative delirium. Sci Rep. 2016;6:29874.

20. Wu T, Sun XY, Yang X, Liu L, Tong K, Gao Y, et al. Histone H3K9 Trimethylation Downregulates the Expression of Brain-Derived Neurotrophic Factor in the Dorsal Hippocampus and Impairs Memory Formation During Anaesthesia and Surgery. Front Mol Neurosci. 2019;12:246.

21. Holter SM, Garrett L, Einicke J, Sperling B, Dirscherl P, Zimprich A, et al. Assessing Cognition in Mice. Curr Protoc Mouse Biol. 2015;5:331-58.

22. Sugar J, Moser MB. Episodic memory: Neuronal codes for what, where, and when. Hippocampus. 2019;29:1190-205. 
23. Vogel-Ciernia A, Wood MA. Examining object location and object recognition memory in mice. Curr Protoc Neurosci. 2014;69:8311-17.

24. Lueptow LM. Novel Object Recognition Test for the Investigation of Learning and Memory in Mice. J Vis Exp. 2017;(126):55718.

25. Broadbent NJ, Gaskin S, Squire LR, Clark RE. Object recognition memory and the rodent hippocampus. Learn Mem. 2010;17:5-11.

26. Leger M, Quiedeville A, Bouet V, Haelewyn B, Boulouard M, Schumann-Bard P, et al. Object recognition test in mice. Nat Protoc. 2013;8:2531-7.

27. Kraeuter AK, Guest PC, Sarnyai Z. The Y-Maze for Assessment of Spatial Working and Reference Memory in Mice. Methods Mol Biol. 2019;1916:105-11.

28. Hao JR, Sun N, Lei L, Li XY, Yao B, Sun K, et al. L-Stepholidine rescues memory deficit and synaptic plasticity in models of Alzheimer's disease via activating dopamine D1 receptor/PKA signaling pathway. Cell Death Dis. 2015;6:e1965.

29. Sun XY, Zheng T, Yang X, Liu L, Gao SS, Xu HB, et al. HDAC2 hyperexpression alters hippocampal neuronal transcription and microglial activity in neuroinflammation-induced cognitive dysfunction. $\mathrm{J}$ Neuroinflammation. 2019;16:249.

30. Zhu Y, Wang Y, Yao R, Hao T, Cao J, Huang H, et al. Enhanced neuroinflammation mediated by DNA methylation of the glucocorticoid receptor triggers cognitive dysfunction after sevoflurane anesthesia in adult rats subjected to maternal separation during the neonatal period. $J$ Neuroinflammation. 2017;14:6.

31. Liu Q, Sun YM, Huang H, Chen C, Wan J, Ma LH, et al. Sirtuin 3 protects against anesthesia/surgeryinduced cognitive decline in aged mice by suppressing hippocampal neuroinflammation. $\mathrm{J}$ Neuroinflammation. 2021;18:41.

32. Li X, Zhao Q, Wei W, Lin Q, Magnan C, Emami MR, et al. The DNA modification N6-methyl-2'deoxyadenosine ( $\mathrm{m} 6 \mathrm{dA})$ drives activity-induced gene expression and is required for fear extinction. Nat Neurosci. 2019;22:534-44.

33. Pan Z, Li GF, Sun ML, Xie L, Liu D, Zhang Q, et al. MicroRNA-1224 Splicing CircularRNA-Filip1l in an Ago2-Dependent Manner Regulates Chronic Inflammatory Pain via Targeting Ubr5. J Neurosci. 2019;39:2125-43.

34. Cardona AE, Huang D, Sasse ME, Ransohoff RM. Isolation of murine microglial cells for RNA analysis or flow cytometry. Nat Protoc. 2006;1:1947-51.

35. Weber M, Davies JJ, Wittig D, Oakeley EJ, Haase M, Lam WL, et al. Chromosome-wide and promoterspecific analyses identify sites of differential DNA methylation in normal and transformed human cells. Nat Genet. 2005;37:853-62.

36. Day JJ, Childs D, Guzman-Karlsson MC, Kibe M, Moulden J, Song E, et al. DNA methylation regulates associative reward learning. Nat Neurosci. 2013;16:1445-+.

37. Gupta S, Kim, Artis S, Molfese DL, Schumacher A, Sweatt JD, et al. Histone methylation regulates memory formation. J Neurosci. 2010;30:3589-99. 
38. Blaze J, Scheuing L, Roth TL. Differential methylation of genes in the medial prefrontal cortex of developing and adult rats following exposure to maltreatment or nurturing care during infancy. Dev Neurosci. 2013;35:306-16.

39. Sui L, Wang Y, Ju LH, Chen M. Epigenetic regulation of reelin and brain-derived neurotrophic factor genes in long-term potentiation in rat medial prefrontal cortex. Neurobiol Learn Mem. 2012;97:42540.

40. Arend WP, Welgus HG, Thompson RC, Eisenberg SP. Biological properties of recombinant human monocyte-derived interleukin 1 receptor antagonist. J Clin Invest. 1990;85:1694-7.

41. Barrientos RM, Hein AM, Frank MG, Watkins LR, Maier SF. Intracisternal interleukin-1 receptor antagonist prevents postoperative cognitive decline and neuroinflammatory response in aged rats. $J$ Neurosci. 2012;32:14641-8.

42. Abraham J, Jang S, Godbout JP, Chen J, Kelley KW, Dantzer R, et al. Aging sensitizes mice to behavioral deficits induced by central HIV-1 gp120. Neurobiol Aging. 2008;29:614-21.

43. Abraham J, Johnson RW. Central inhibition of interleukin-1 beta ameliorates sickness behavior in aged mice. Brain Behav Immun. 2009;23:396-401.

44. Cibelli M, Fidalgo AR, Terrando N, Ma D, Monaco C, Feldmann M, et al. Role of interleukin-1 beta in postoperative cognitive dysfunction. Ann Neurol. 2010;68:360-8.

45. Yoshioka Y, Sugino Y, Shibagaki F, Yamamuro A, Ishimaru Y, Maeda S. Dopamine attenuates lipopolysaccharide-induced expression of proinflammatory cytokines by inhibiting the nuclear translocation of NF-kappaB p65 through the formation of dopamine quinone in microglia. Eur $\mathrm{J}$ Pharmacol. 2020;866:172826.

46. Simón C, Piquette GN, Frances A, Polan ML. Localization of interleukin-1 type I receptor and interleukin-1 beta in human endometrium throughout the menstrual cycle. J Clin Endocrinol Metab. 1993;77:549-55.

47. Jones ME, Lebonville CL, Paniccia JE, Balentine ME, Reissner KJ, Lysle DT. Hippocampal interleukin1 mediates stress-enhanced fear learning: A potential role for astrocyte-derived interleukin-1 beta. Brain Behav Immun. 2018;67:355-63.

48. Flannery S, Bowie AG. The interleukin-1 receptor-associated kinases: critical regulators of innate immune signalling. Biochem Pharmacol. 2010;80:1981-91.

49. Ringwood L, Li L. The involvement of the interleukin-1 receptor-associated kinases (IRAKs) in cellular signaling networks controlling inflammation. Cytokine. 2008;42:1-7.

50. Huang Y, Smith DE, Ibanez-Sandoval O, Sims JE, Friedman WJ. Neuron-specific effects of interleukin1 beta are mediated by a novel isoform of the IL-1 receptor accessory protein. $J$ Neurosci. 2011;31:18048-59.

51. Guasch RM, Blanco AM, Perez-Arago A, Minambres R, Talens-Visconti R, Peris B, et al. RhoE participates in the stimulation of the inflammatory response induced by ethanol in astrocytes. Exp Cell Res. 2007;313:3779-88. 
52. Barter JD, Foster TC. Aging in the Brain: New Roles of Epigenetics in Cognitive Decline. Neuroscientist. 2018;24:516-25.

53. Cui L, Sun W, Yu M, Li N, Guo L, Gu H, et al. Disrupted-in-schizophrenia1 (DISC1) L100P mutation alters synaptic transmission and plasticity in the hippocampus and causes recognition memory deficits. Mol Brain. 2016;9:89.

54. Haettig J, Stefanko DP, Multani ML, Figueroa DX, McQuown SC, Wood MA. HDAC inhibition modulates hippocampus-dependent long-term memory for object location in a CBP-dependent manner. Learn Mem. 2011;18:71-9.

55. Vogel-Ciernia A, Matheos DP, Barrett RM, Kramar EA, Azzawi S, Chen Y, et al. The neuron-specific chromatin regulatory subunit BAF53b is necessary for synaptic plasticity and memory. Nat Neurosci. 2013;16:552-61.

56. Tanimizu T, Kono K, Kida S. Brain networks activated to form object recognition memory. Brain Res Bull. 2018;141:27-34.

57. Kong Q, Yu M, Zhang M, Wei C, Gu H, Yu S, et al. Conditional Dnmt3b deletion in hippocampal dCA1 impairs recognition memory. Mol Brain. 2020;13:42.

58. Chen L, Xie W, Xie W, Zhuang W, Jiang C, Liu N. Apigenin attenuates isoflurane-induced cognitive dysfunction via epigenetic regulation and neuroinflammation in aged rats. Arch Gerontol Geriatr. 2017;73:29-36.

59. Luo F, Hu Y, Zhao W, Zuo Z, Yu Q, Liu Z, et al. Maternal Exposure of Rats to Isoflurane during Late Pregnancy Impairs Spatial Learning and Memory in the Offspring by Up-Regulating the Expression of Histone Deacetylase 2. PLoS One. 2016;11:e0160826.

60. Liu J, Wang P, Zhang X, Zhang W, Gu G. Effects of different concentration and duration time of isoflurane on acute and long-term neurocognitive function of young adult C57BL/ 6 mouse. Int $\mathrm{J}$ Clin Exp Pathol. 2014;7:5828-36.

61. Jia M, Liu WX, Yang JJ, Xu N, Xie ZM, Ju LS, et al. Role of histone acetylation in long-term neurobehavioral effects of neonatal Exposure to sevoflurane in rats. Neurobiol Dis. 2016;91:209-20.

62. Silbert BS, Evered LA, Scott DA. Incidence of postoperative cognitive dysfunction after general or spinal anaesthesia for extracorporeal shock wave lithotripsy. Br J Anaesth. 2014;113:784-91.

63. Avramescu S, Wang DS, Lecker I, To WT, Penna A, Whissell PD, et al. Inflammation Increases Neuronal Sensitivity to General Anesthetics. Anesthesiology. 2016;124:417-27.

64. Kubota K, Suzuki A, Ohde S, Yamada U, Hosaka T, Okuno F, et al. Age is the Most Significantly Associated Risk Factor With the Development of Delirium in Patients Hospitalized for More Than Five Days in Surgical Wards: Retrospective Cohort Study. Ann Surg. 2018;267:874-7.

65. Zhao G, Deng J, Shen Y, Zhang P, Dong H, Xie Z, et al. Hyperhomocysteinemia is key for increased susceptibility to PND in aged mice. Ann Clin TransI Neurol. 2019;6:1435-44.

66. Skvarc DR, Berk M, Byrne LK, Dean OM, Dodd S, Lewis M, et al. Post-Operative Cognitive Dysfunction: An exploration of the inflammatory hypothesis and novel therapies. Neurosci Biobehav Rev. 2018;84:116-33. 
67. Nimmerjahn A, Kirchhoff F, Helmchen F. Resting microglial cells are highly dynamic surveillants of brain parenchyma in vivo. Science. 2005;308:1314-8.

68. Xu Y, Xu Y, Wang Y, Wang Y, He L, Jiang Z, et al. Telmisartan prevention of LPS-induced microglia activation involves M2 microglia polarization via CaMKKbeta-dependent AMPK activation. Brain Behav Immun. 2015;50:298-313.

69. Qiu LL, Ji MH, Zhang H, Yang JJ, Sun XR, Tang H, et al. NADPH oxidase 2-derived reactive oxygen species in the hippocampus might contribute to microglial activation in postoperative cognitive dysfunction in aged mice. Brain Behav Immun. 2016;51:109-18.

70. Li Y, Pan K, Chen L, Ning JL, Li X, Yang T, et al. Deferoxamine regulates neuroinflammation and iron homeostasis in a mouse model of postoperative cognitive dysfunction. J Neuroinflammation. 2016;13:268.

71. Sun L, Dong R, Xu X, Yang X, Peng M. Activation of cannabinoid receptor type 2 attenuates surgeryinduced cognitive impairment in mice through anti-inflammatory activity. J Neuroinflammation. 2017;14:138.

72. Ballweg T, White M, Parker M, Casey C, Bo A, Farahbakhsh Z, et al. Association between plasma tau and postoperative delirium incidence and severity: a prospective observational study. $\mathrm{Br} \mathrm{J}$ Anaesth. 2021;126:458-66.

73. Iovino F, Orihuela CJ, Moorlag HE, Molema G, Bijlsma JJ. Interactions between blood-borne Streptococcus pneumoniae and the blood-brain barrier preceding meningitis. PLoS One. 2013;8:e68408.

74. Heller JP, Rusakov DA. Morphological plasticity of astroglia: Understanding synaptic microenvironment. Glia. 2015;63:2133-51.

75. Chucair-Elliott AJ, Ocanas SR, Stanford DR, Ansere VA, Buettner KB, Porter H, et al. Inducible cellspecific mouse models for paired epigenetic and transcriptomic studies of microglia and astroglia. Commun Biol. 2020;3:693.

76. Penner MR, Roth TL, Chawla MK, Hoang LT, Roth ED, Lubin FD, et al. Age-related changes in Arc transcription and DNA methylation within the hippocampus. Neurobiol Aging. 2011;32:2198-210.

77. Penner MR, Parrish RR, Hoang LT, Roth TL, Lubin FD, Barnes CA. Age-related changes in Egr1 transcription and DNA methylation within the hippocampus. Hippocampus. 2016;26:1008-20.

78. Mangold CA, Masser DR, Stanford DR, Bixler GV, Pisupati A, Giles CB, et al. CNS-wide Sexually Dimorphic Induction of the Major Histocompatibility Complex 1 Pathway With Aging. J Gerontol A Biol Sci Med Sci. 2017;72:16-29.

79. Oliveira AM. DNA methylation: a permissive mark in memory formation and maintenance. Learn Mem. 2016;23:587-93.

80. Rajasethupathy P, Antonov I, Sheridan R, Frey S, Sander C, Tuschl T, et al. A role for neuronal piRNAs in the epigenetic control of memory-related synaptic plasticity. Cell. 2012;149:693-707.

81. Mohammad F, Pandey GK, Mondal T, Enroth S, Redrup L, Gyllensten U, et al. Long noncoding RNAmediated maintenance of DNA methylation and transcriptional gene silencing. Development. 
2012;139:2792-803.

82. Zhang Y, Jurkowska R, Soeroes S, Rajavelu A, Dhayalan A, Bock I, et al. Chromatin methylation activity of Dnmt3a and Dnmt3a/3L is guided by interaction of the ADD domain with the histone $\mathrm{H} 3$ tail. Nucleic Acids Res. 2010;38:4246-53.

83. Ooi SK, Qiu C, Bernstein E, Li K, Jia D, Yang Z, et al. DNMT3L connects unmethylated lysine 4 of histone $\mathrm{H} 3$ to de novo methylation of DNA. Nature. 2007;448:714-7.

84. Otani J, Nankumo T, Arita K, Inamoto S, Ariyoshi M, Shirakawa M. Structural basis for recognition of H3K4 methylation status by the DNA methyltransferase 3A ATRX-DNMT3-DNMT3L domain. Embo Rep. 2009;10:1235-41.

85. Lebedeva TV, Singh AK. Constitutive activity of the murine IL-1 beta promoter is regulated by a transcriptional repressor. Biochim Biophys Acta. 1997;1353:32-8.

86. Jarome TJ, Butler AA, Nichols JN, Pacheco NL, Lubin FD. NF-kappaB mediates Gadd45beta expression and DNA demethylation in the hippocampus during fear memory formation. Front Mol Neurosci. 2015;8:54.

87. Cho SH, Chen JA, Sayed F, Ward ME, Gao F, Nguyen TA, et al. SIRT1 deficiency in microglia contributes to cognitive decline in aging and neurodegeneration via epigenetic regulation of IL-1 beta. J Neurosci. 2015;35:807-18.

88. Youm YH, Grant RW, McCabe LR, Albarado DC, Nguyen KY, Ravussin A, et al. Canonical Nlrp3 inflammasome links systemic low-grade inflammation to functional decline in aging. Cell Metab. 2013;18:519-32.

89. Murray CA, Lynch MA. Evidence that increased hippocampal expression of the cytokine interleukin-1 beta is a common trigger for age- and stress-induced impairments in long-term potentiation. $J$ Neurosci. 1998;18:2974-81.

90. Liu Y, Zhang Y, Zheng X, Fang T, Yang X, Luo X, et al. Galantamine improves cognition, hippocampal inflammation, and synaptic plasticity impairments induced by lipopolysaccharide in mice. $J$ Neuroinflammation. 2018;15:112.

\section{Figures}


a

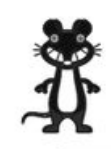

Aged:18moths

Adult: 3 moths b

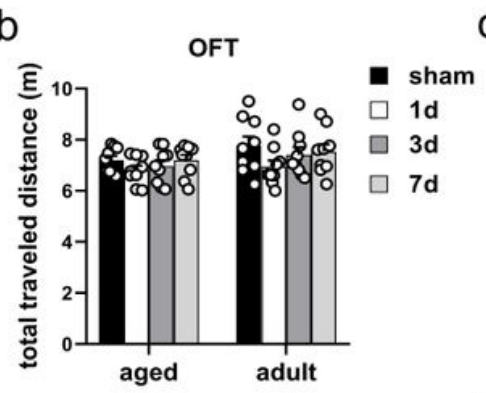

e

d

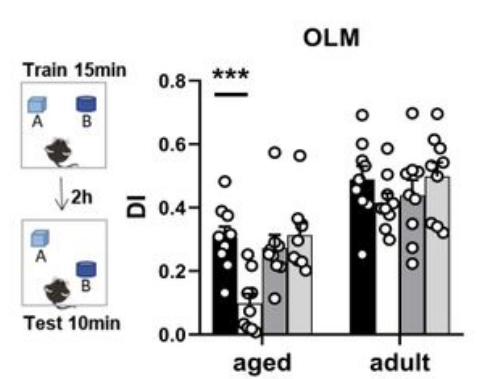

g

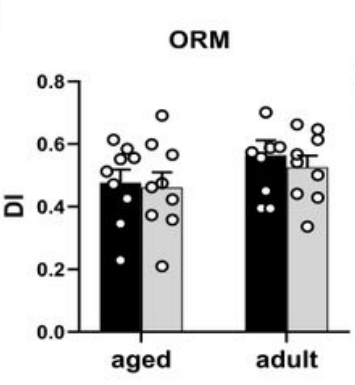

1d, $3 d, 7 d$

after surgery
C
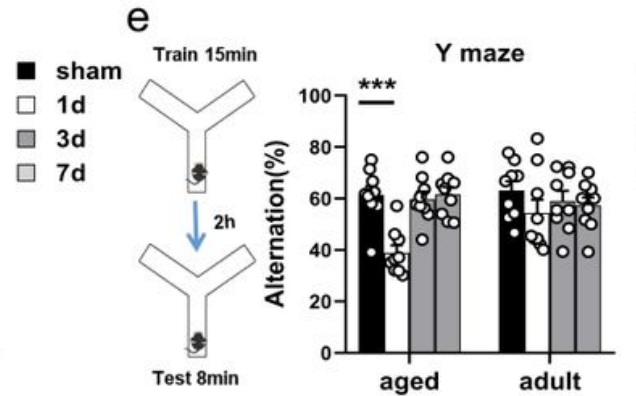

- sham

$\square$ 1d

$\square 3 d$

$\square 7 d$

$f$

OLM

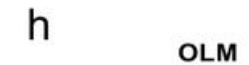

Con
$\square$ Iso
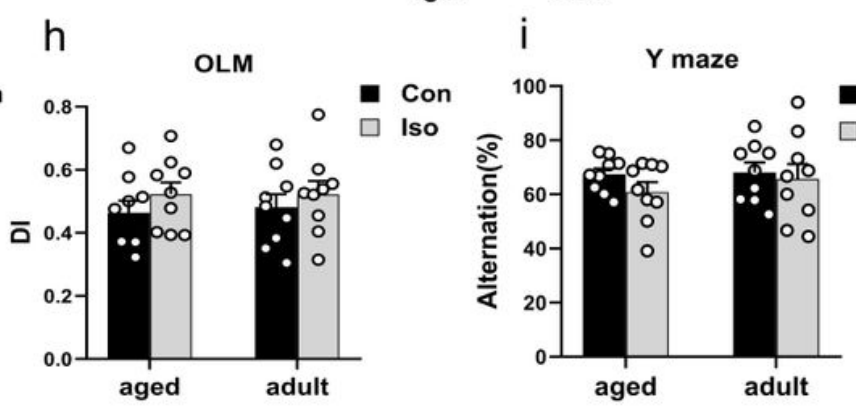
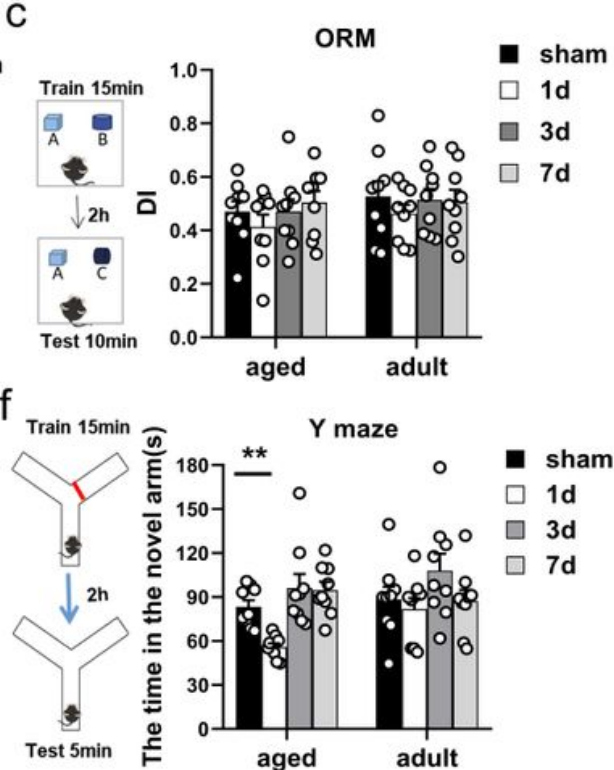

- sham

$\square$ 1d

월

$\circ$

$\square$ 3d
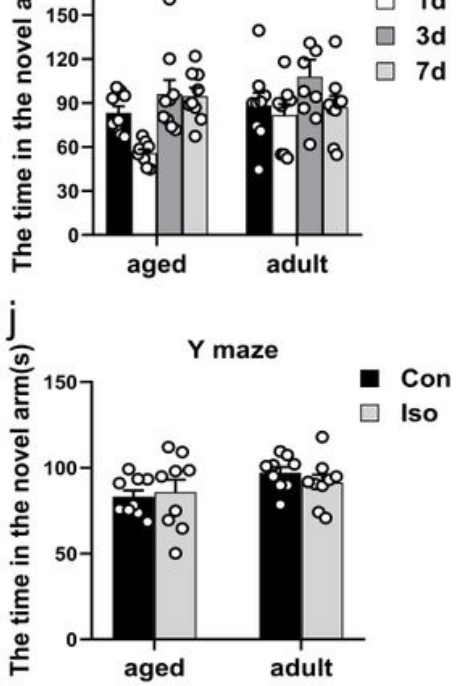

Figure 1

Surgery but not anesthesia impaired hippocampus-dependent cognition of aged mice. (a) Experimental design, 3 or 18-month-old C57/BL mice were conduct laparotomy in the chamber filled with $1.4-2 \%$ isoflurane for $20 \mathrm{~min}$. Open filed, Y-maze and novel object tests were performed at different time points.

(b) The mice showed normal total travelled distance in the open field test. (c-d) the DI of aged mice were decreased in OLM, but not ORM, in 1d group. The spontaneous alternation index (e) and the time in the novel arm (f) of aged mice were decreased in $Y$ maze in 1d group. (g-j) Simple anesthesia had no effect on the cognitive function of adult and aged mice. Data are presented as mean $\pm S E M . n=9 .{ }^{*} P<0.01$, $\star \star \star P<0.001$ versus corresponding group. 

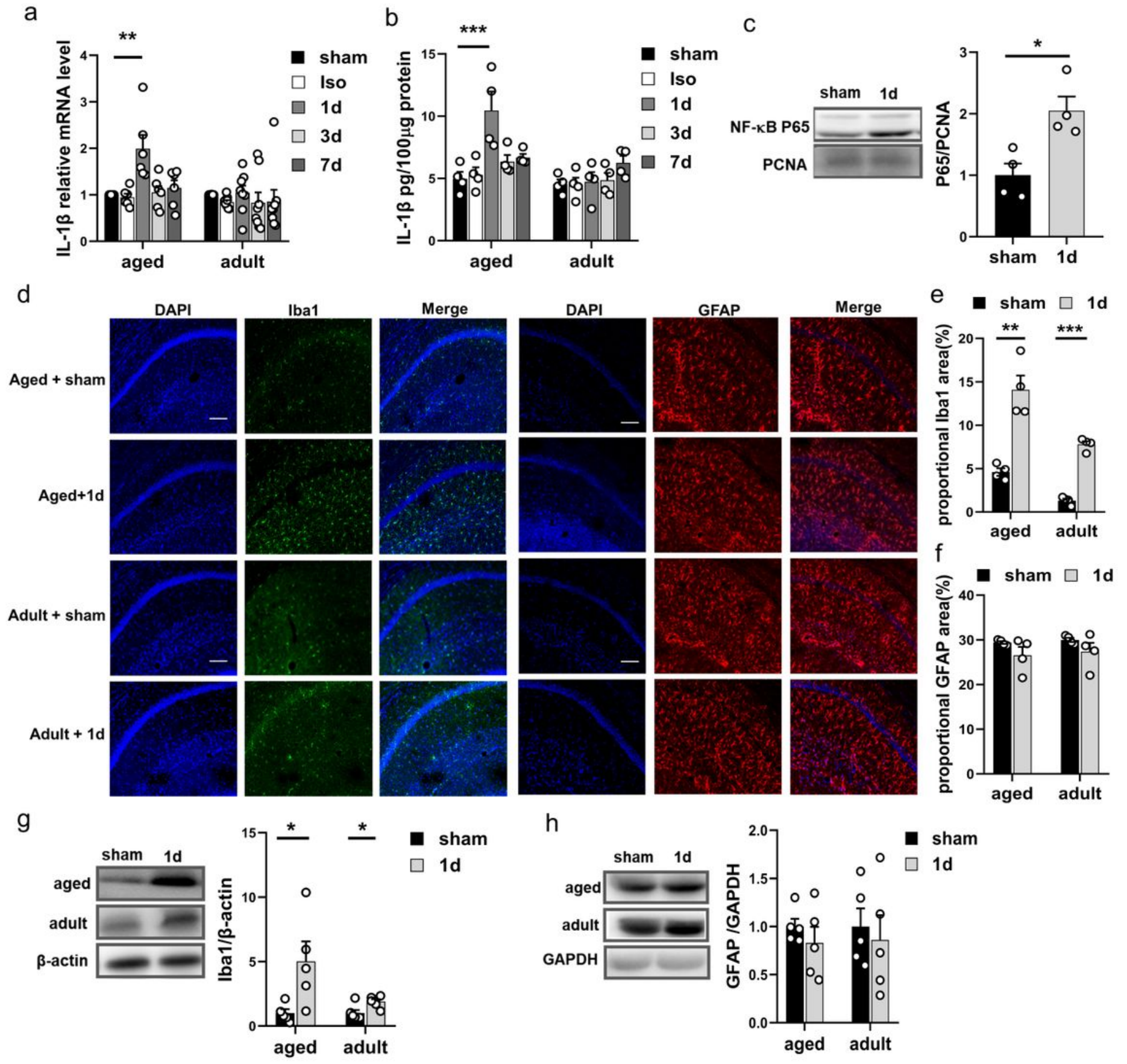

Figure 2

The microglia in the dorsal hippocampus was activated after surgery. (a-b) The protein and mRNA levels of IL-1 $\beta$ in dorsal hippocampus were increased in the aged+1d group. (c) The expression of NF-KB P65 in dorsal hippocampus nucleus of aged mice were increased at 1 day after surgery. (d) Representative images of Iba1 and GFAP in the CA1 region at day 1 after surgery (scale bar $=100 \mu \mathrm{m})$. (e-f)

Quantification of Iba1 and GFAP fluorescence. ( $g-h)$ The expression of Iba1 was significantly increased in the $1 \mathrm{~d}$ group of aged and adult mice, while GFAP showed no significant change in the $1 \mathrm{~d}$ group compared with the sham group. $n=4-6$. Data are presented as mean $\pm S E M .{ }^{*} P<0.05,{ }^{*} P<0.01, * \star * P<$ 0.001 versus corresponding group. 
a

b
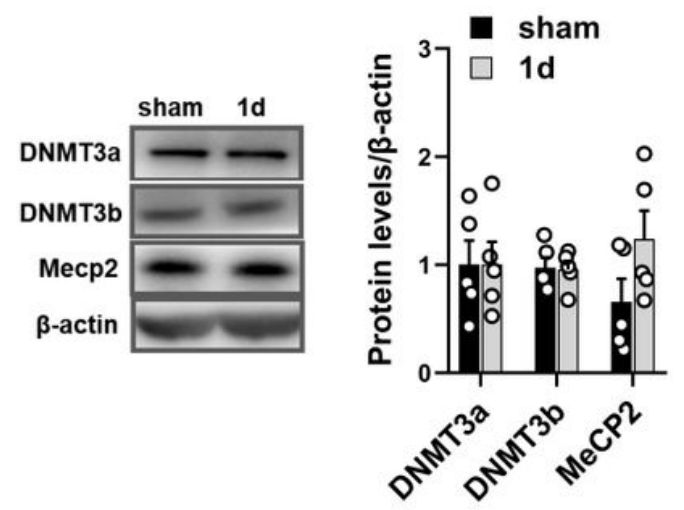

C
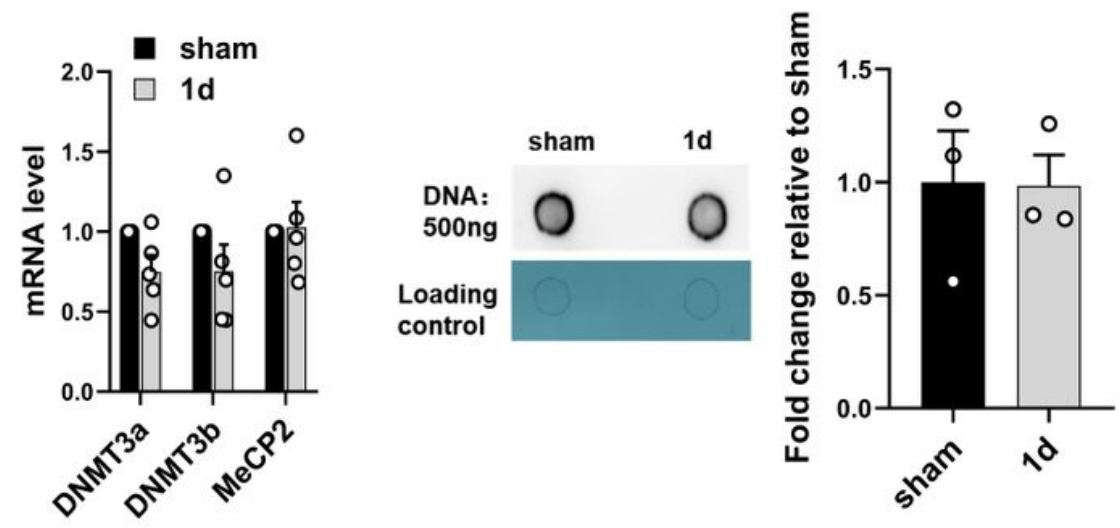

e
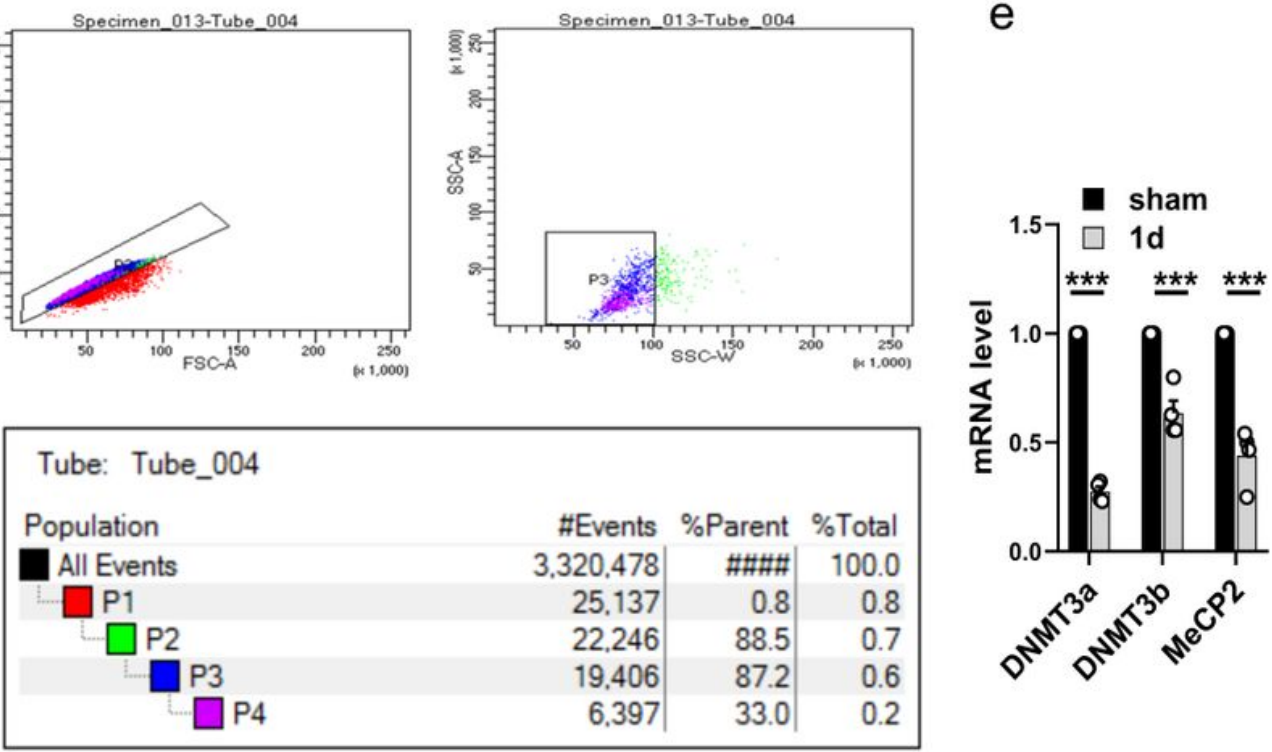

Figure 3

Epigenetic regulators were altered by surgery in sorted microglia but remained unchanged in dorsal hippocampus. The western blot (a) and RT-PCR (b) showed no difference in the expression of DNMT3a, DNMT3b, MeCP2 between 1d group and sham group in dorsal hippocampus of aged mice. (c) The global $5 \mathrm{mC}$ level was also no difference between $1 \mathrm{~d}$ group and sham group in dorsal hippocampus of aged mice. (d) the microglia were sorted by flow cytometry from aged dorsal hippocampus. (e) mRNA of DNMT3a, DNMT3b and MeCP2 were decreased in sorted microglia from aged dorsal hippocampus at $1 \mathrm{~d}$ after surgery. Data are presented as mean \pm SEM. $n=3-5, \star \star \star P<0.001$ versus corresponding group. 
a

Mouse IL-1 $\beta$ promotor

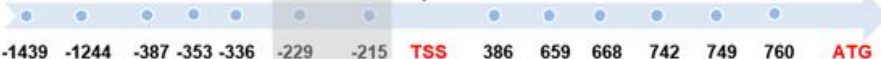

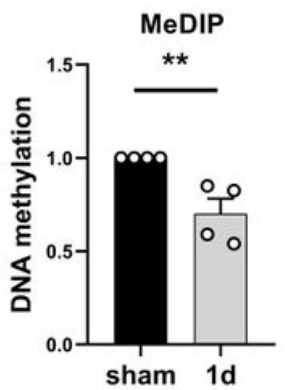

C

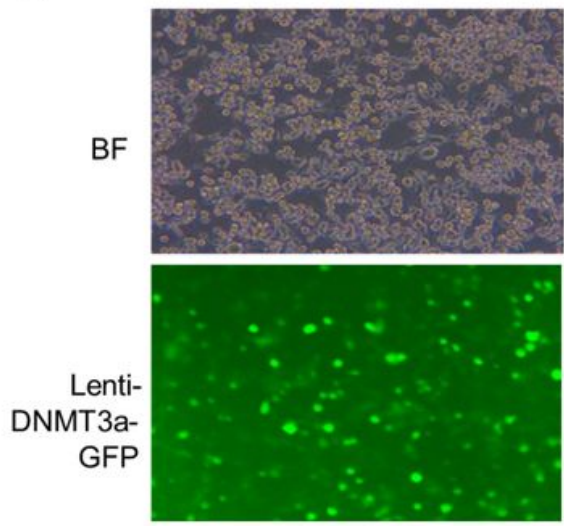

b
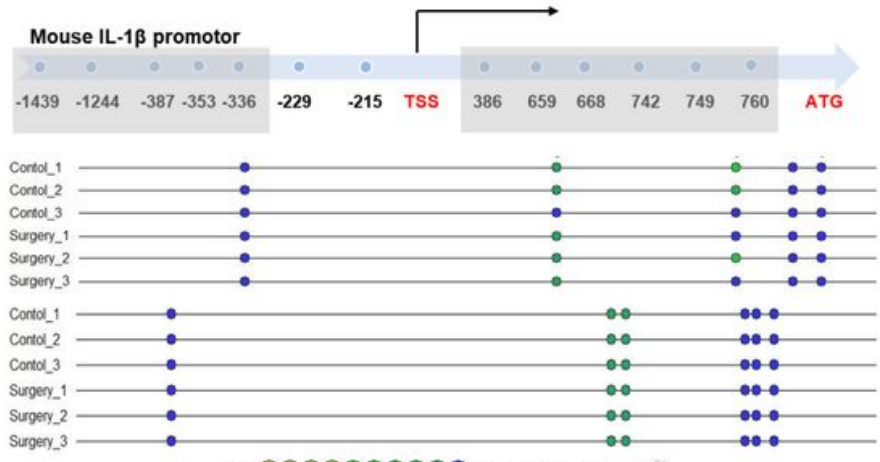

$0 \% \bigcirc 00000000100 \%$ Not analyzed:

Color scale of methylation degree

$\mathrm{e}_{\text {Lenti- Empty }}$ оNмT3a Empty DNMT3a

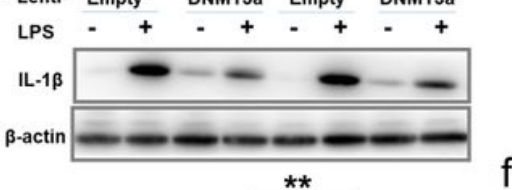

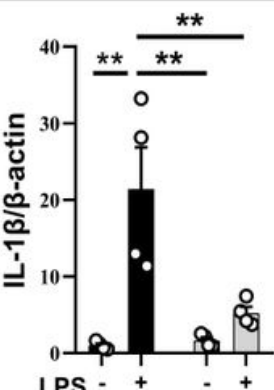

Lenti-Empty $\overline{\text { DNMT } 3 a}$

$f$

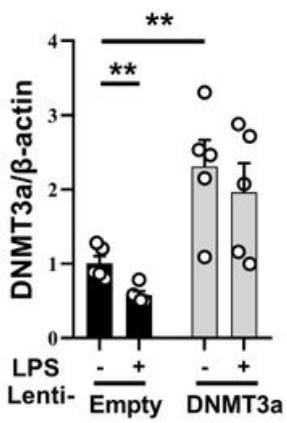

denti- Empty DNMT3a

LPS - $+\cdot+$

DNMT3a

$\beta$-actin

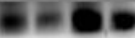$$
\text { in }
$$

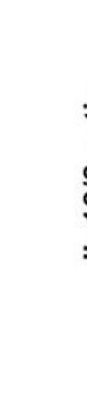

\section{Figure 4}

DNA methylation played a direct role in IL-1 $\beta$ gene regulation. (a) MeDIP and MSP showed that the DNA methylation level of IL-1 $\beta$ promoter region in aged mice was significantly decreased at 1 day after surgery at the site of $-215,-229$. But not in other CpG sites of IL-1 $\beta$ (b). (c) BV2 cells were well infected with LentiGFP. (d-f) Overexpression of DNMT3a in BV2 cells reversed the increase of IL-1 $\beta$ induced by LPS and the decrease of DNA methylation levels of IL-1 $\beta$. Data are presented as mean \pm SEM. $n=3-5 .{ }^{*} P<0.05,{ }^{\star *} P<$ 0.01 versus corresponding group. 


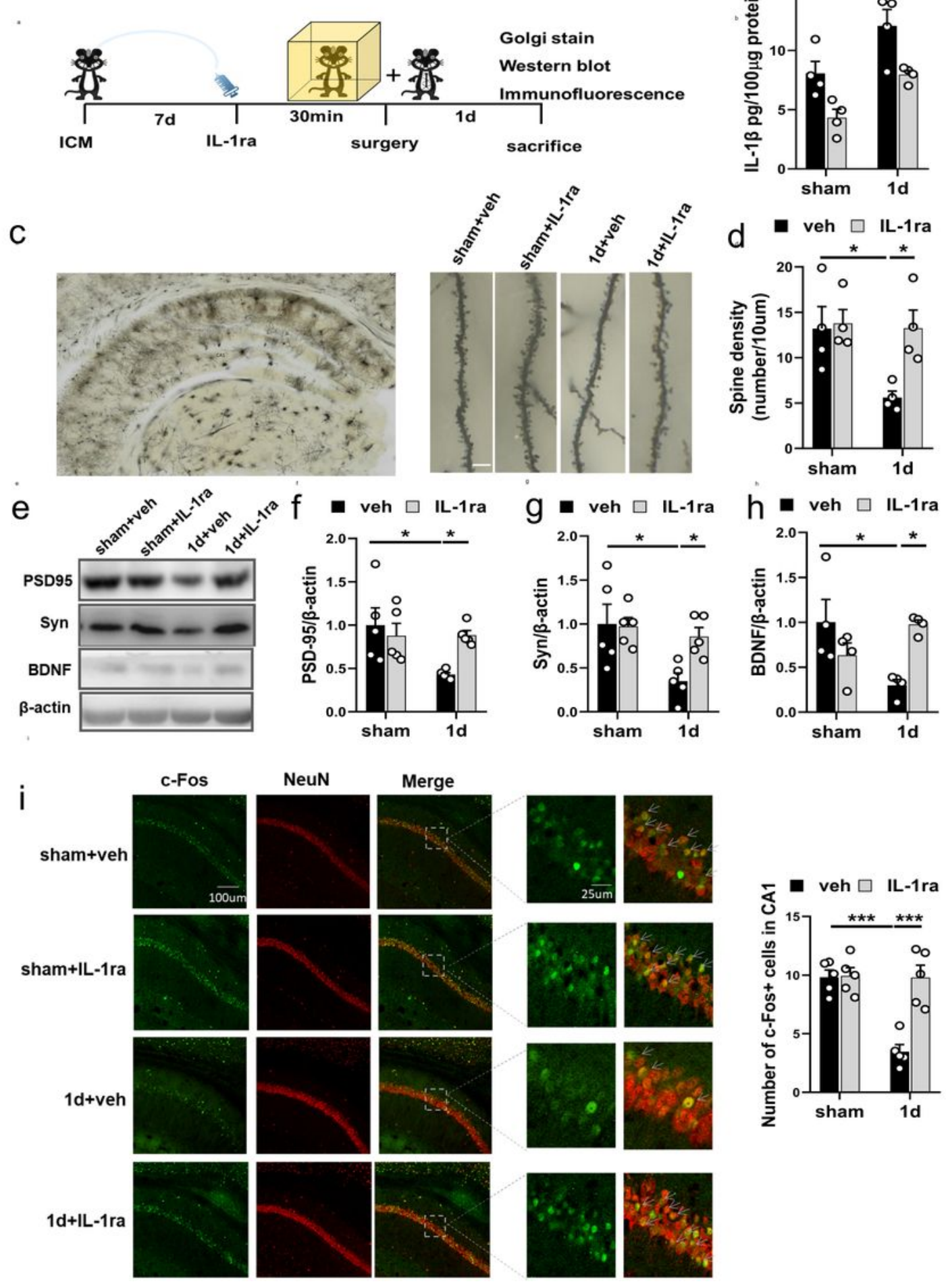

\section{Figure 5}

Effects of inhibiting IL-1 $\beta$ on synaptic plasticity in the dorsal hippocampus of aged mice with POCD. (a) Experimental design. (b) a single administration of IL-1 ra could prevent the surgery-induced IL-1 $\beta$ elevations in aged mice at 1 day after surgery. (c-d) IL-1 ra could reverse the decrease of dendritic spine density in the dorsal hippocampus of aged mice one day after surgery. (Scale bar $=5 \mu \mathrm{m})$. (e-h) IL-1 ra could reverse the decrease of PSD95, Syn, BDNF in the dorsal hippocampus of aged mice one day after 
surgery. (i) surgery reduced the number of c-Fos+ neurons in the dorsal hippocampus of aged mice, and IL-1 ra could reverse it. $n=4-5$. Data are presented as mean $\pm S E M, * P<0.05,{ }^{\star} * \star P<0.001$ versus corresponding group.
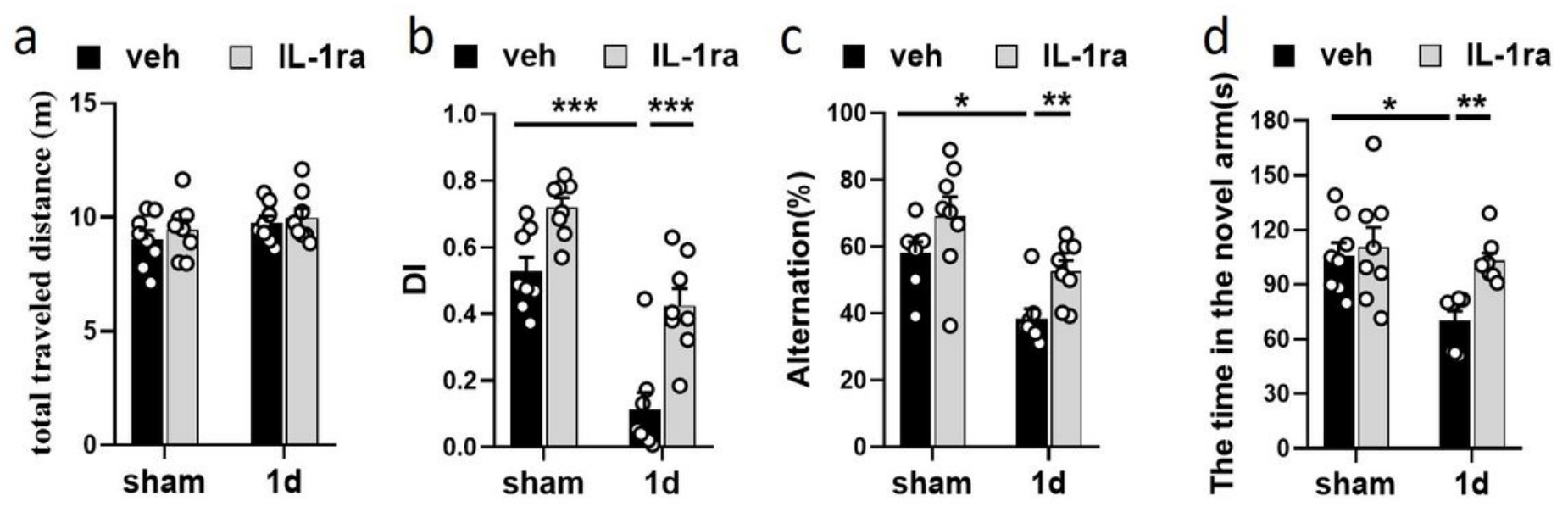

Figure 6

Effects of inhibiting IL-1 $\beta$ on cognition of aged mice with POCD. (a) The mice showed normal total travelled distance in the open field test. (b-d) the discrimination ratio, the spontaneous alternation index, and the time in the novel arm of aged mice was reversed by inhibiting IL-1 $\beta$ by administration of IL-1 ra. Data are presented as mean \pm SEM. $n=8 .{ }^{*} P<0.05,{ }^{\star} P P<0.01,{ }^{\star} * \star P<0.001$ versus corresponding group.

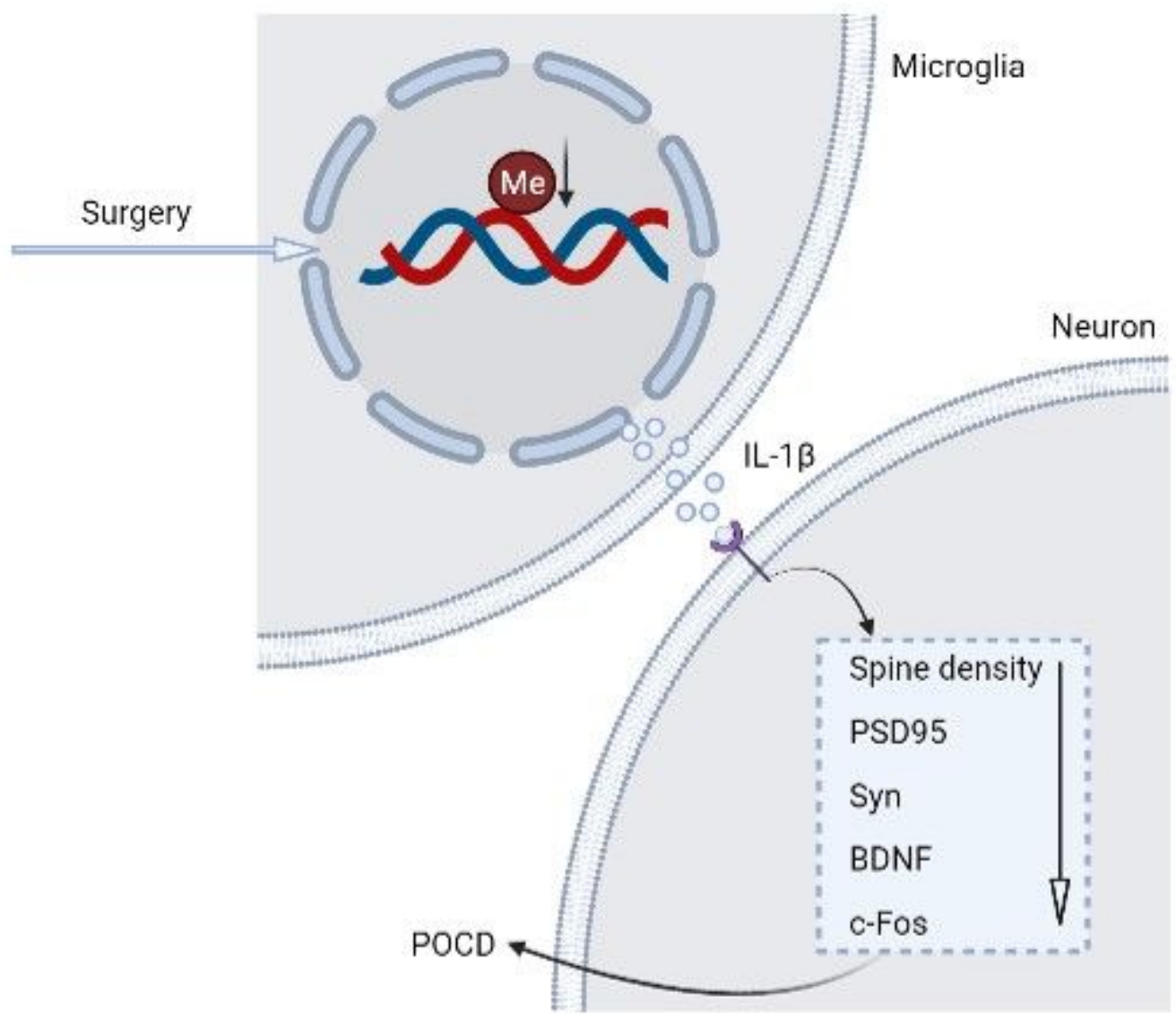


Figure 7

Schematic representation of the role of IL-1 $\beta$ and DNA methylation in learning and memory deficits associated with surgery in aged mice.

\section{Supplementary Files}

This is a list of supplementary files associated with this preprint. Click to download.

- additionalfile1.pdf

- additionalfile2.pdf 